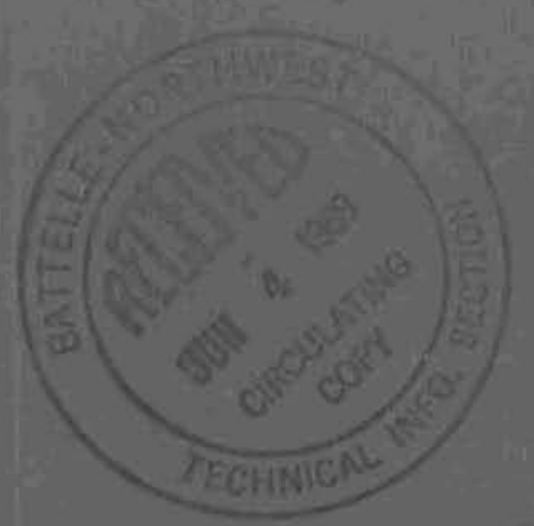

BNWL-760 Sup Supplement 1 UC- 80

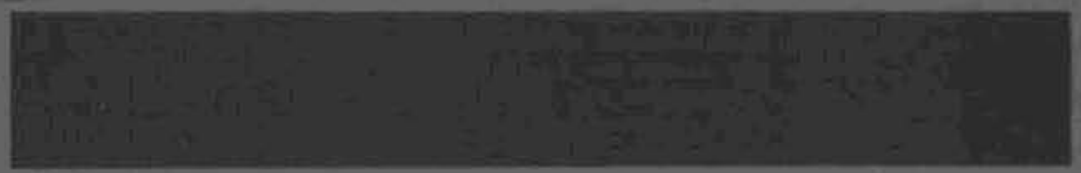

\title{
PRELIMINARY ANALYSIS OF POSTULATED MAXIMUM ACCIDENTS FOR THE FFTF
} SUPPLEMENT I-ADDITIONAL CALCULATIONS FOR SODIUM-IN CONDITIONS December 1968

\section{AEC RESEARCH \& DEVELOPMENT REPORT}

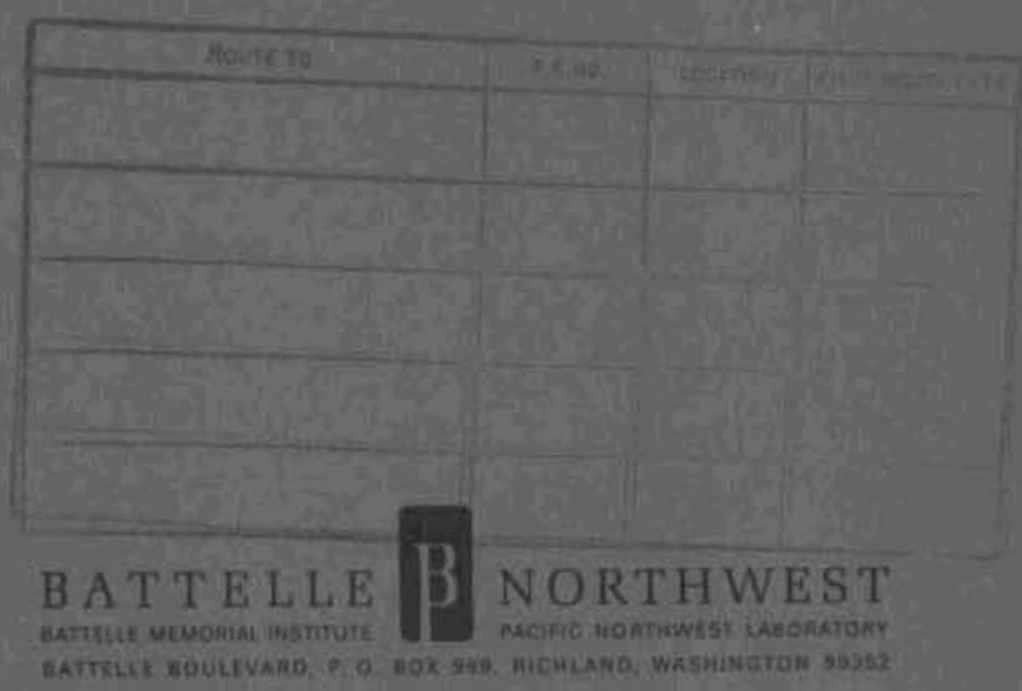




\section{LEGAL NOTICE}

This feport was prepared os an arcount of Government sponsoted Work. Nelther the United States, nor the Commission, nor any person acting an bahalf of the Commission:

A. Makes any worranty or representation, expressed or implied, with respect to the occuracy, com. pleteness, or usefulness of the information contained in this report, or that the use of any information, apporatus method, of process disclosed in this report moy not infringe privately owned rights; on

B. Assumes any. liabilities with respect to the use of, or for damoges resulting from the use of any information, apparalus, method, or process disclosed in this report.

As used in the obave, "person acting an behalf of the Commission" includes ony amployee or contractor of the Commission, or employee of such contractor, to the oxtent ihat such employee or canfractor of the Commission; or employee of such contractor prepares, disseminates, or provides occess to, any information pursuant to his employment or contract-with the Commission, or his employmant with such conlractor:

\section{PACIFIC NORTHWEST LABORATORY}

RICHLAND, WASHINGTON

operated by

BATTELLE MEMORIAL INSTITUTE

for the

UNITED STATES ATOMIC ENERGY COMMISSION UNDER CONTRACT AT(45-1)-1830 


\title{
PRELIMINARY ANALYSIS OF POSTULATED MAXIMUM ACCIDENTS FOR THE FFTF SUPPLEMENT I - ADDITIONAL CALCULATIONS FOR SODIUM-IN CONDITIONS
}

\author{
By \\ R. A. Harris \\ Reactor Physics and Operations Department \\ FFTF Project
}

December 1968

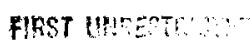

Mo: $: 2$

BATTELLE MEMORIAL INSTITUTE PACIFIC NORTHWEST LABORATORY RICHLAND, WASHINGTON 99352 
BNWL -760

Supplement 1

Printed in the United States of America Available from

Clearinghouse for Federal Scientific and Technical Information National Bureau of Standards, U.S. Department of Commerce

Springfield, Virginia 22151

Price: Printed Copy $\$ 3.00 ;$ Microfiche $\$ 0.65$ 
BNWL -760

Supplement 1

\author{
PRELIMINARY ANALYSIS OF POSTULATED \\ MAXIMUM ACCIDENTS FOR THE FFTF \\ SUPPLEMENT I - ADDITIONAL CALCULATIONS \\ FOR SODIUM-IN CONDITIONS
}

R. A. Harris

\title{
ABSTRACT
}

This document contains a reevaluation of the core disassemb1y calculations reported in BNWL-760 for the particular case of "sodium-in" conditions. The validity of the "sodiumin" equation of state used in the referenced document is. reexamined, and a newly developed expression, based on experimental data in the temperature domain of interest, is presented. The effect of sodium vapor pressure as a disassembly force and the effects of sodium compressibility are parametrically examined.

The analysis indicates that the disassembly calculations reported in BNWL-760 for "sodium-in" conditions are probably quite pessimistic. However, a reevaluation of the effects of sodium prior to and following the disassembly phase may be necessary before one can confidently recommend energy release values which are substantially lower than those previously reported. 
.

•

-

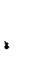




\section{TABLE OF CONTENTS}

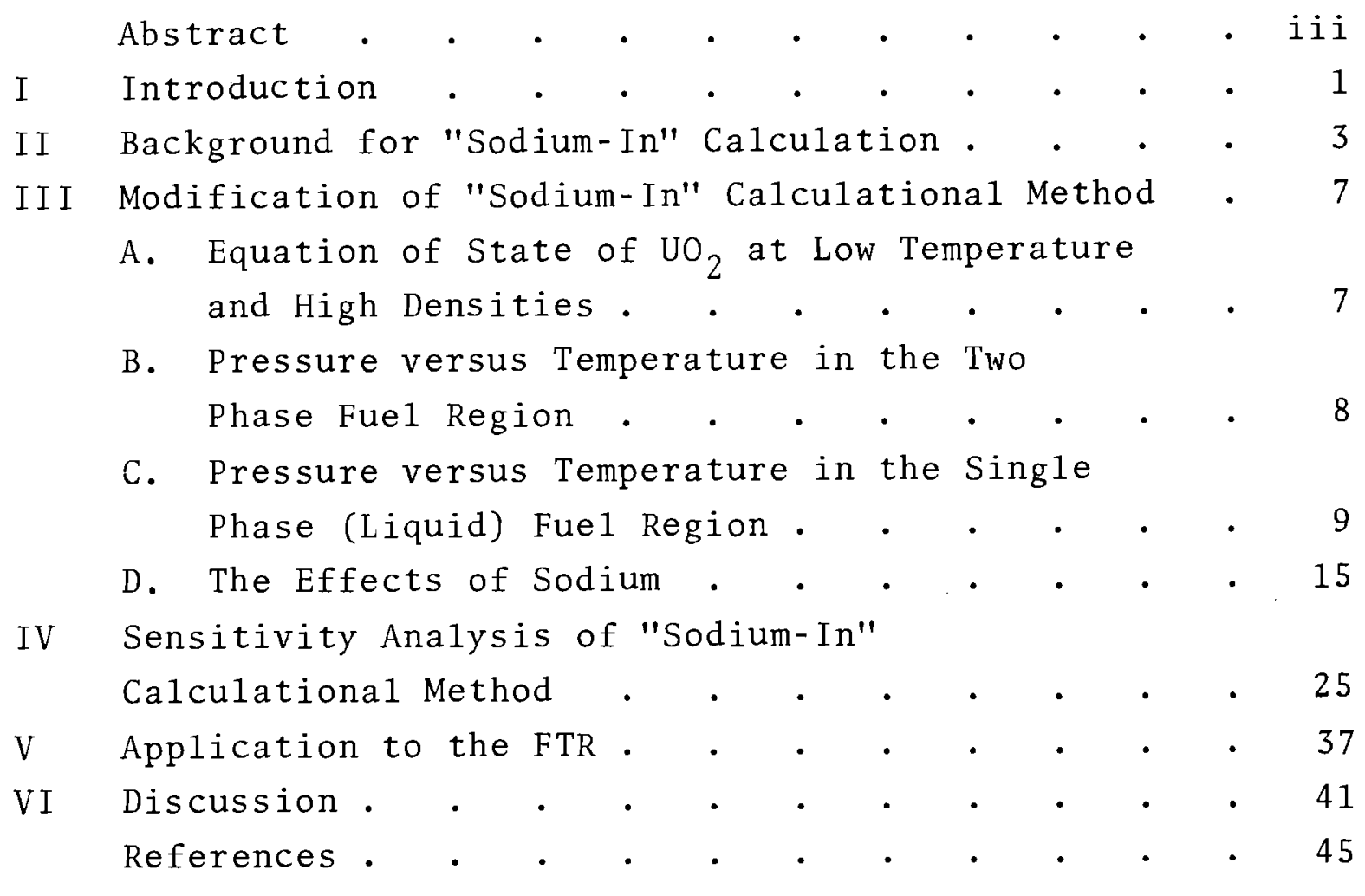


BNWL- 760

Supplement 1

\section{LIST OF FIGURES}

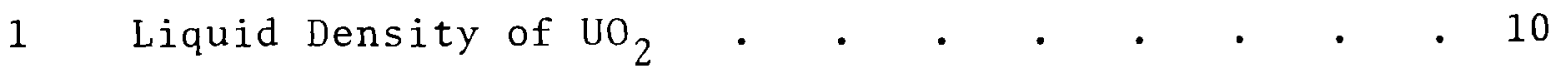

2 Pressure-Temperature Relationship from Corresponding

States. . . . . . . . . . . . 12

3 Comparison of Pressure-Temperature Slopes in Liquid

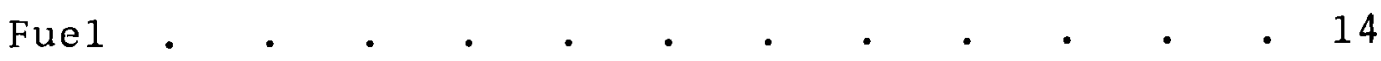

4 Adiabatic Compressibility of Sodium . . . . . . 18

5 Effect of Sodium Compressibility on Pressure in the

Pure Liquid Fuel Region . . . . . . . 20

6 Effect of Sodium Compressibility on Temperature at

which Pure Liquid Fuel Phase Begins . . . . 21

7 Effect of Sodium Compressibility on Pressure

Temperature Slopes in Pure Liquid Fuel Region. . 22

8 Power Distribution Employed in the Disassembly Phase. 26

9 Fuel Worth Distribution Employed in the Disassembly

Phase. . . . . . . . . . . . 27

10 Sensitivity of Volumetric Coefficient of Expansion

of Liquid Fuel. . . . . . . . . . 30

11 Sensitivity of Fuel Density at Melting Point. • . 30

12 Sensitivity of Sodium Compressibility . . . . 32

13 Sensitivity of Sodium Content . . . . . . 34 
BNWL - 760

Supplement 1

\author{
PRELIMINARY ANALYSIS OF POSTULATED \\ MAXIMUM ACCIDENTS FOR THE FFTF \\ SUPPLEMENT I - ADDITIONAL CALCULATIONS \\ FOR SODIUM-IN CONDITIONS
}

R. A. Harris

\title{
I. INTRODUCTION
}

A preliminary analysis of postulated maximum accidents for the FTR has recently been published (BNWL-760). (1) In that analysis, the disassembly phase was generally handled in the same manner as in previous calculations at Hanford $(2)^{\circ}$ and other $(3,4,5)$ sites. The major exception was that, under certain circumstances, the sodium coolant was assumed to have remained in the core during the disassembly process. This "sodium-in" analysis was quite approximate because of the simplifying assumptions which were made. The purpose of this report is to investigate additional phenomena associated with "sodium-in" core disassembly accidents in order to provide a better basis for interpreting some of the results of the preliminary calculations published in BNWL-760, November 1968 . 


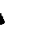

. 
BNWL -760

Supplement 1

\section{BACKGROUND FOR "SODIUM-IN" CALCULATION}

The pressures that provide the forces required to disassemble the core in a disassembly accident are generally assumed to be only those exerted by the hot fuel. These pressures arise from two distinct sources: fuel vapor and heated confined liquids. If a sufficient volume is available to the fuel, a two phase fuel system will exist over a wide temperature range. The pressures are then those exerted by the fuel vapor and can be calculated from a vapor pressure relationship. Since the mole fraction in the vapor state can vary, the resulting pressures are virtually independent of the volume available to the 1iquid-vapor system. However, as the temperature of the system increases or the volume available decreases, the liquid fuel phase may fill all of the available volume. The resulting pressures are characteristic of a heated, confined liquid and such pressures rise very rapidly with small increases in fuel temperature. These pressures are quite sensitive to the available volume, since a small increase in volume may be sufficient to allow the existence of a vapor phase.

The amount of void in the core at the start of the disassembly process affects the volume available to the fuel and, thus, can significantly alter the total energy generated in a disruptive accident. For large voids, the liquid phase will not expand enough during the accident to fill the available volume. As the initial void volume decreases, the energy generated will remain constant until the volume is such that departure from a two phase fuel system occurs before disassembly is completed. Since the pressures exerted by the confined liquid phase are significantly higher than those obtained from the vapor pressure relationship, disassembly occurs at a faster rate, and the energy generated is correspondingly reduced. As the void volume continues to decrease, the generated energy 
BNWL- 760

Supplement 1

required for disassembly will decrease quite rapidly, since the liquid phase fills the available volume at lower temperatures and high pressures arise earlier in time.

The presence or absence of the sodium coolant in the disassembly phase is a sensitive parameter since it can significantly alter the volume available to the fuel (sodium occupies about 40 vol\% of the FFTF core). Typically, previous maximum accident studies $(2,3,4,5)$ have assumed that the sodium is not present during the disassembly phase. Such an assumption is justified from the standpoint of being conservative since excluding the sodium will increase the amount of energy required to disassemble the core. Furthermore, unless the course of the accident prior to disassembly is carefully specified, it would be difficult to ensure that the sodium will be present throughout the entire core. This assumption of total voiding makes it unnecessary to include in the calculations the complications that may arise from the presence of sodium.

Most of the disruptive nuclear excursions considered in BNWL-760 (1) were analyzed assuming that the sodium was not present. This conservative approach was taken since in most instances the disposition of the sodium was not specified even though the accidents, once initiated, were carefully followed through disassembly. A few calculations were made, however, in which the effects of sodium were considered. It was found that if a positive voiding coefficient existed near the center of the core, and if a rather rapid rate of central void was assumed, the reactivity ramp at the start of disassembly was substantially increased. Also in these cases, it was assumed that the hot fuel existing at the end of the nuclear excursion could mix with the sodium coolant. The resulting hot sodium, when expanded, yielded more available work than if the fue 1 itself had been expanded for the same initial accident conditions. 
BNWL - 760

Supplement 1

Both of these sodium effects significantly increased the estimated energy available to do destructive work on the core surroundings. In effort to treat the sodium-in situation consistently, however, the mitigating effects of sodium during the disassembly process (i.e., the reduction in the available volume for fuel expansion and the partial inclusion of sodium pressure as a disassembly force) were included in the calculations. The assumption of the presence of the sodium has been justified by the fact that its adverse effects were calculated assuming that it was in the core initially and remained until after disassembly.

The previous attempt to describe the disassembly process in the presence of sodium utilized several simplifying assumptions. These assumptions may, however, have a significant effect on the results. First, it was assumed that the equation of state generated in BNWL-760 for use in "sodium-out" calculations could also be used without modification for the "sodium-in" cases by merely specifying a smaller volume available to the fuel. The "sodium-in" disassembly calculations, however, resulted in final fuel temperatures significantly lower than the temperatures assumed when the equation of state was originally obtained. Also, the primary disassembly pressure mechanism for the "sodium-in" cases was that of the confined liquid and not the pressure of the fuel vapor. Furthermore, the sodium was assumed to be inert in that it only occupied a specified constant volume. This approximation disregarded the fact that ( 1 ), the sodium was a finite compressibility and (2), it may reduce the fuel temperatures by acting as a heat sink. In order to estimate the effects of the assumptions made, the fuel equation of state was reevaluated and several sodium effects were investigated. The remainder of this report describes this investigation and the resulting changes to the preliminary ${ }^{(1)}$ calculations. 


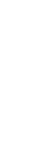

. 
BNWL - 760

Supplement 1

\section{MODIFICATION OF "SODIUM-IN" CALCULATIONAL METHOD}

\section{A. EQUATION OF STATE OF UO 2 AT LOW TEMPERATURES AND HIGH DENSITIES}

An equation of state for fuel material was generated in BNWL-760 for use in "sodium-out" calculations. The fuel properties were assumed to be those of $\mathrm{UO}_{2}$ since only a relatively small amount of $\mathrm{PuO}_{2}$ will be present and the two oxides are intimately mixed. This same assumption was made for the "sodium-in" and "sodium-out" calculations. This fact prompted the present modifications to the equation of state to reflect the changed areas of emphasis more accurately.

The final fuel temperatures in the "sodium-in" cores considered for the FFTF are not much beyond the melting point. It was, therefore, deemed desirable to make the equation of state extrapolate as closely as possible to whatever low temperature data is available. Table 1 shows the low temperature data used in this study. The previous equation of state employed the corresponding states principle throughout. This principle states that all substances behave similarly when described in terms of the reduced variables of state. These are the ratio of the actual value to the value of the variable at the critical point [i.e., reduced temperature $\left(\mathrm{T}_{\mathrm{r}}\right)=$ actual temperature/critical temperature]. The tables of Hougen et a1. (6) were then used to obtain the pressure temperature and energy relationship required. Within the range of critical compressibility tabulated, it was not possible to match al1 of the low temperature data. It was therefore concluded that, where needed, methods other than the principle of corresponding states would be used for estimating the equation of state. 
BNWL -760

Supplement 1

TABLE 1. Low Temperature Data Used in UO 2 Equation of State Determination

Parameter

Melting temperature

Liquid density at melting point

Volumetric

Coefficient of

expansion at

melting point

Vapor pressure at melting point

$$
\begin{array}{ll}
\frac{\text { Value }}{\mathrm{T}_{\mathrm{o}}=3070^{\circ} \mathrm{K}} & \frac{\text { Reference }}{\text { Christensen }}(7) \\
\rho_{\mathrm{o}}=8.74 \mathrm{~g} / \mathrm{cm}^{3} & \text { Christensen }(7) \\
\frac{1}{\rho}\left(\frac{\partial \rho}{\partial \mathrm{T}}\right)=-\alpha & \text { Christensen }(7) \\
\cong-1.05 \times 10^{-4}{ }^{\circ} \mathrm{K}^{-1} & \\
\mathrm{P}_{\mathrm{vp}} \cong 0.06 \rightarrow 0.01 \text { atm } & \begin{array}{c}
\text { Ackermann } \\
\text { (extrapolated) }
\end{array}
\end{array}
$$

In this report, only the pressure-temperature relationships were investigated. (Constant specific heat value of $0.42 \mathrm{~J} / \mathrm{g}-{ }^{\circ} \mathrm{K}$ was assumed to relate temperature to energy.) If the density of the fuel in its available volume is small, the vapor pressure curve describes the system adequately. For large densities, however, both the temperature at which the liquid fuel fills the available volume and the relationship between pressure and temperature in the pure liquid phase must be specified. The following sections describe the method and values as sumed to obtain the required relationships.

\section{B. PRESSURE VERSUS TEMPERATURE IN THE TWO PHASE FUEL REGION}

Several methods are available for estimating the vapor pressure of the 1 iquid; the reduced equation of Riede1 (6) matched to the vapor pressure measurements of Ackermann, (8) or an extension of the Ackermann data itself. The equation used in this study was:

$$
P=\exp \left\{55.455-\frac{78847}{\mathrm{~T}}-4.2808 \ln \mathrm{T}\right\}
$$

where

$$
\begin{aligned}
& \mathrm{P}=\text { pressure in atmospheres, and } \\
& \mathrm{T}=\text { temperature in }{ }^{\circ} \mathrm{K} .
\end{aligned}
$$


BNWL - 760

Supplement 1

At $3070^{\circ} \mathrm{K}$, this equation yields a pressure of 0.01 atm which is on the conservative (lowest pressure) side of the extrapolated data.

As will be shown later for the calculations performed in this study, that vapor pressure has little effect on the disassemb1y process.

C. PRESSURE VERSUS TEMPERATURE IN THE SINGLE PHASE (LIQUID) FUEL REGION

The temperature at which the fuel system departs from the vapor pressure curve (liquid fills all of the available volume) was estimated from the measurements of Christensen. (7) $\mathrm{He}$ found that the melting temperature, liquid density at the me1ting point, and linear coefficient of expansion at the melting point of $\mathrm{UO}_{2}$ were $3070{ }^{\circ} \mathrm{K}, 8.74 \mathrm{~g} / \mathrm{cm}^{3}$, and $3.5 \times 10^{-5}{ }^{\circ} \mathrm{K}^{-1}$, respectively. From this data, it was estimated that the volumetric coefficient of expansion $(\alpha)$ was about $1.05 \times 10^{-4}{ }^{\circ} \mathrm{K}^{-1}$. Disregarding any pressure dependence, the liquid density was then estimated to be

$$
\begin{aligned}
\rho & =\rho_{0}\left[1-\alpha\left(\mathrm{T}-\mathrm{T}_{\mathrm{O}}\right)\right] \\
& =8.74\left[1-1.05 \times 10^{-4}(\mathrm{~T}-3070)\right] \mathrm{g} / \mathrm{cm}^{3} .
\end{aligned}
$$

This equation can be used to determine the departure temperature for a given fuel system by letting $\rho$ equal the density of the fuel in its available volume. Thus,

$$
\begin{aligned}
\mathrm{T}_{\mathrm{d}} & =\left(1-\frac{\rho}{\rho_{\mathrm{o}}}\right) \frac{1}{\alpha}+\mathrm{T}_{\mathrm{o}} \\
& =\left(1-\frac{\rho}{8.74}\right) \frac{1}{1.05 \times 10^{-4}}+3070^{\circ} \mathrm{K} .
\end{aligned}
$$

The temperature dependence of the liquid fuel density proposed for this study is shown in Figure 1 along with the temperature-density relationship inherent in the equation of state used 


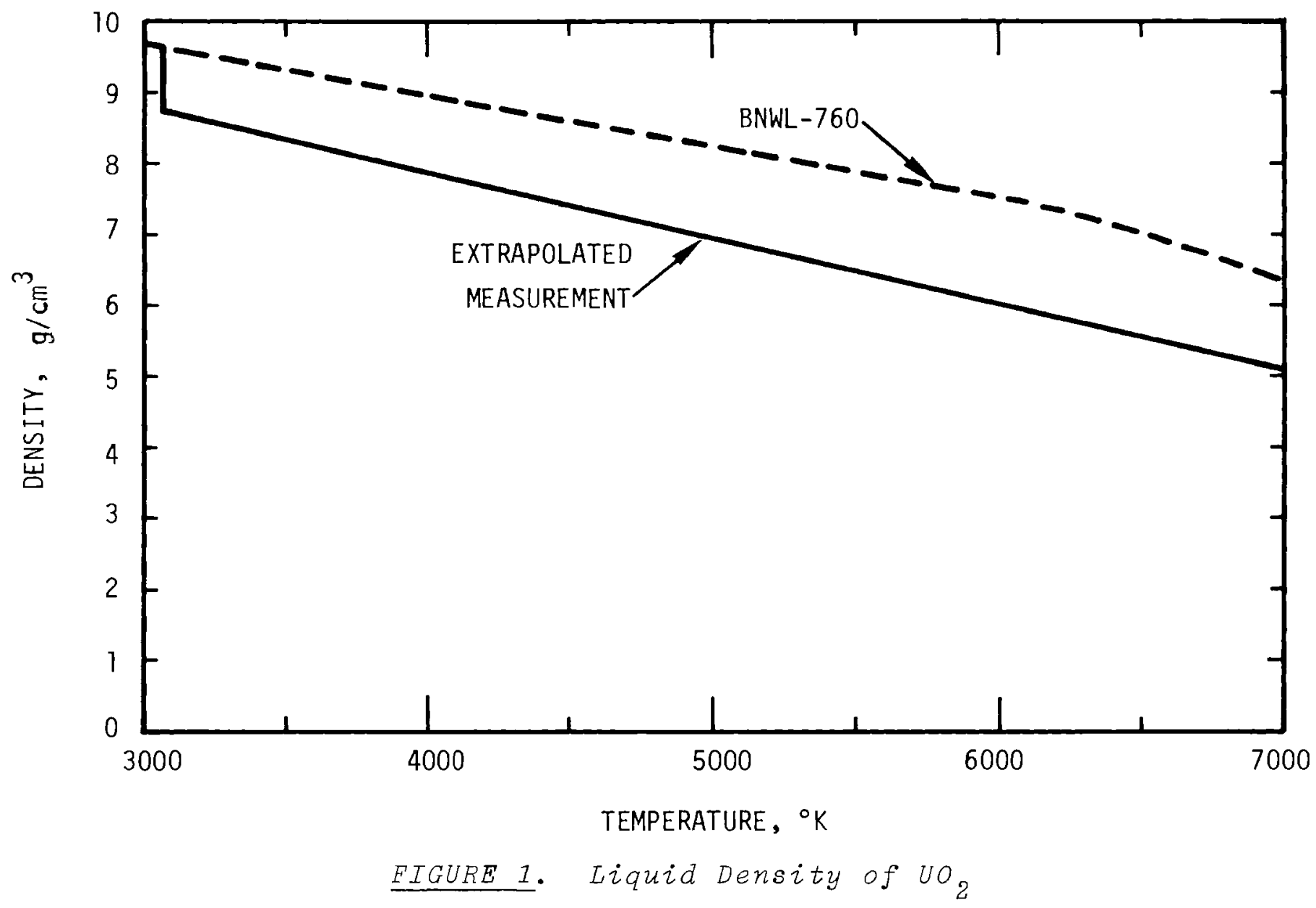


BNWL - 760

Supplement 1

in BNWL-760. It is obvious that the present relationship will cause the high pressures associated with the confined liquid to occur at lower temperatures for a given fuel density.

The extrapolated data relationship is shown as a straight line even though it should have a downward curve (at least near the critical point). Miller(9) utilized Christensen's data and the "law of rectilinear diameters" to construct a temperature-density relationship up to the critical point. From his plot, it was estimated that a linear temperaturedensity relationship was quite adequate over the temperature range of interest in this study. In any event, any downward curve in the relationship would cause departure to occur at lower temperatures, and thus, the linear relationship would be conservative.

Once the fuel system has entered the pure liquid region, it was assumed that the slope of the pressure temperature curve was a constant for a given fuel density, i.e.,

$$
\left.\frac{\partial \mathrm{P}}{\partial \mathrm{T}}\right)_{\rho}=\mathrm{f}(\rho)
$$

An estimate of $f(\rho)$ was obtained from the corresponding states tables of Hougen et al. (6) The plot (for an assumed critical compressibility of 0.27 ) in Figure 2 indicates that the straight line approximation is quite adequate. An analytic fit to this figure is

$$
\left.\frac{\partial \mathrm{P}_{\mathrm{r}}}{\partial \mathrm{T}_{\mathrm{r}}}\right)_{\rho_{\mathrm{r}}}=\rho_{\mathrm{r}} \exp \left[2.0958+0.430\left(\rho_{\mathrm{r}}-0.832\right)^{2}\right]
$$

where

$$
\begin{aligned}
& \mathrm{P}_{\mathrm{r}}=\text { reduced pressure, } \\
& \mathrm{T}_{\mathrm{r}}=\text { reduced temperature, and } \\
& \rho_{\mathrm{r}}=\text { reduced density }
\end{aligned}
$$




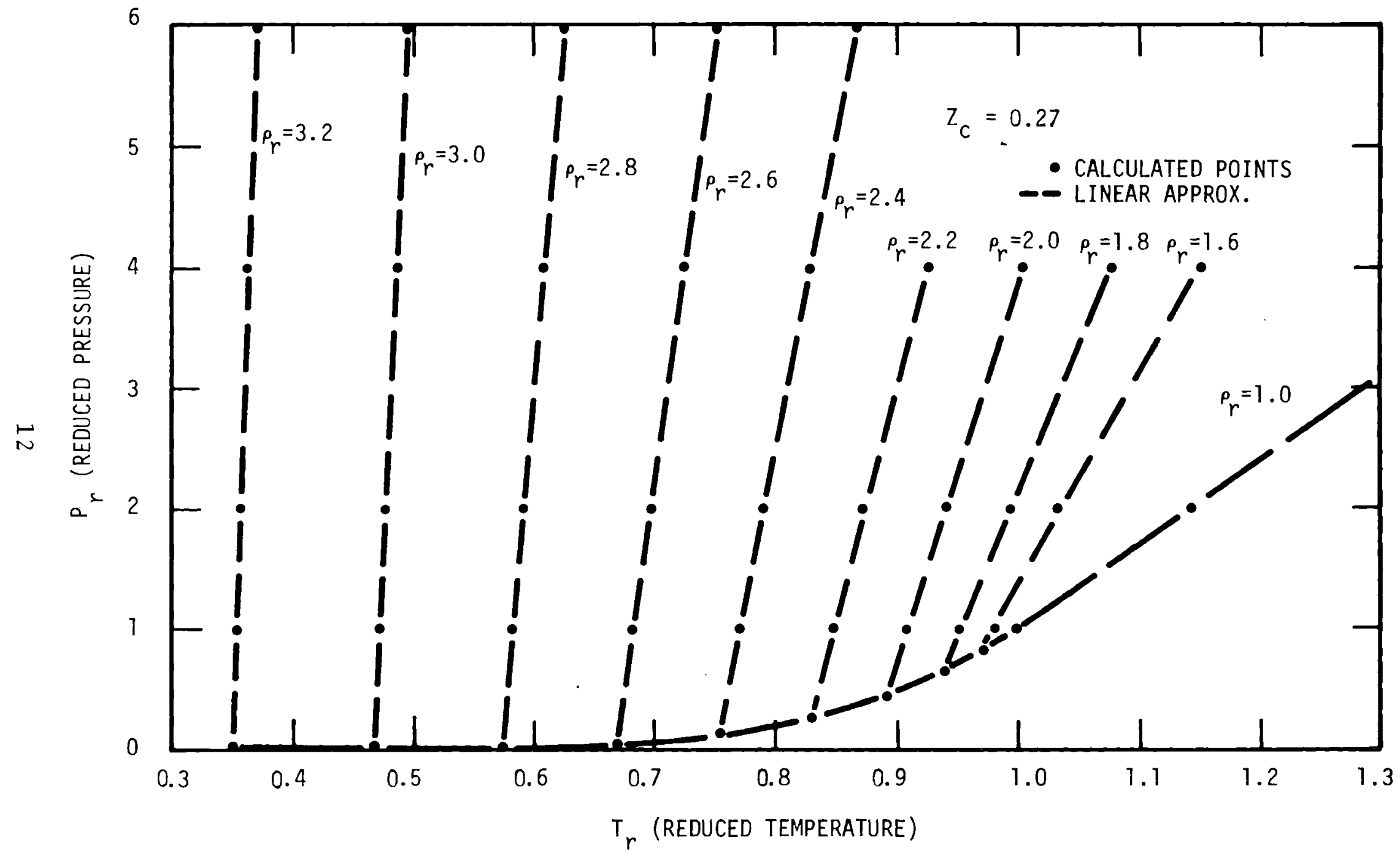

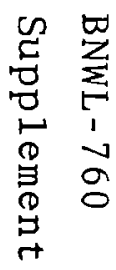

EIGURE 2. Pressure-Temperature Relationship from Corresponding States 
BNWL- 760

Supplement 1

or,

$$
\left.\frac{\partial P}{\partial T}\right)_{\rho}=\frac{R \rho 0.27}{M} \exp \left[2.0958+0.430\left(\rho_{r}-0.832\right)^{2}\right]
$$

where

$$
\begin{aligned}
& \mathrm{P}=\text { pressure, } \\
& \mathrm{T}=\text { temperature, } \\
& \rho=\text { density, } \\
& \mathrm{M}=\text { molecular weight of fue } 1, \text { and } \\
& \mathrm{R}=\text { gas constant. }
\end{aligned}
$$

If a critical density $\left(\rho_{c}\right)$ of $3.0 \mathrm{~g} / \mathrm{cm}^{3}$ is assumed,

$$
\left.\frac{\partial \mathrm{P}}{\partial \mathrm{T}}\right)_{\rho}=\rho 0.666 \exp \left[0.048(\rho-2.5)^{2}\right] \text {. }
$$

The value $\rho_{c}=3.0 \mathrm{~g} / \mathrm{cm}^{3}$ was obtained from the Meyer $(10)$ and Menzies (11) critical constants. Had a lower value been assumed (i.e., Miller's ${ }^{(9)}=1.59 \mathrm{~g} / \mathrm{cm}^{3}$ ), the slopes would have been larger. In Figure 3 these slopes are compared with those obtained by extrapolating the equation of state in BNWL-760 to low temperatures. Again, the present slopes are smaller. A comparison was also made between slopes and the estimates of Robbins. (12) When a specific heat of $0.42 \mathrm{~J} / \mathrm{g}-{ }^{\circ} \mathrm{K}$ and a critical density of $3.0 \mathrm{~g} / \mathrm{cm}^{3}$ is assumed, the maximum slope (at $8.74 \mathrm{~g} / \mathrm{cm}^{3}$ ) is $124 \mathrm{~atm} /{ }^{\circ} \mathrm{K}$. The slopes derived in this study a1so reach a maximum for a density of $8.74 \mathrm{~g} / \mathrm{cm}^{3}$; however, the value is only $38 \mathrm{~atm} /{ }^{\circ} \mathrm{K}$. Thus, although the principle of corresponding states may not accurately describe the liquid fuel, the slopes assumed for this study are significantly less then those obtained by any other method, and they thereby lead to conservative results.

The pressure-temperature relationship in the liquid fuel region can thus be written as,

$$
\left.P=\frac{\partial P}{\partial T}\right)_{\rho}\left(T-T_{d}\right)+P_{d}
$$


BNWL - 760

Supplement 1

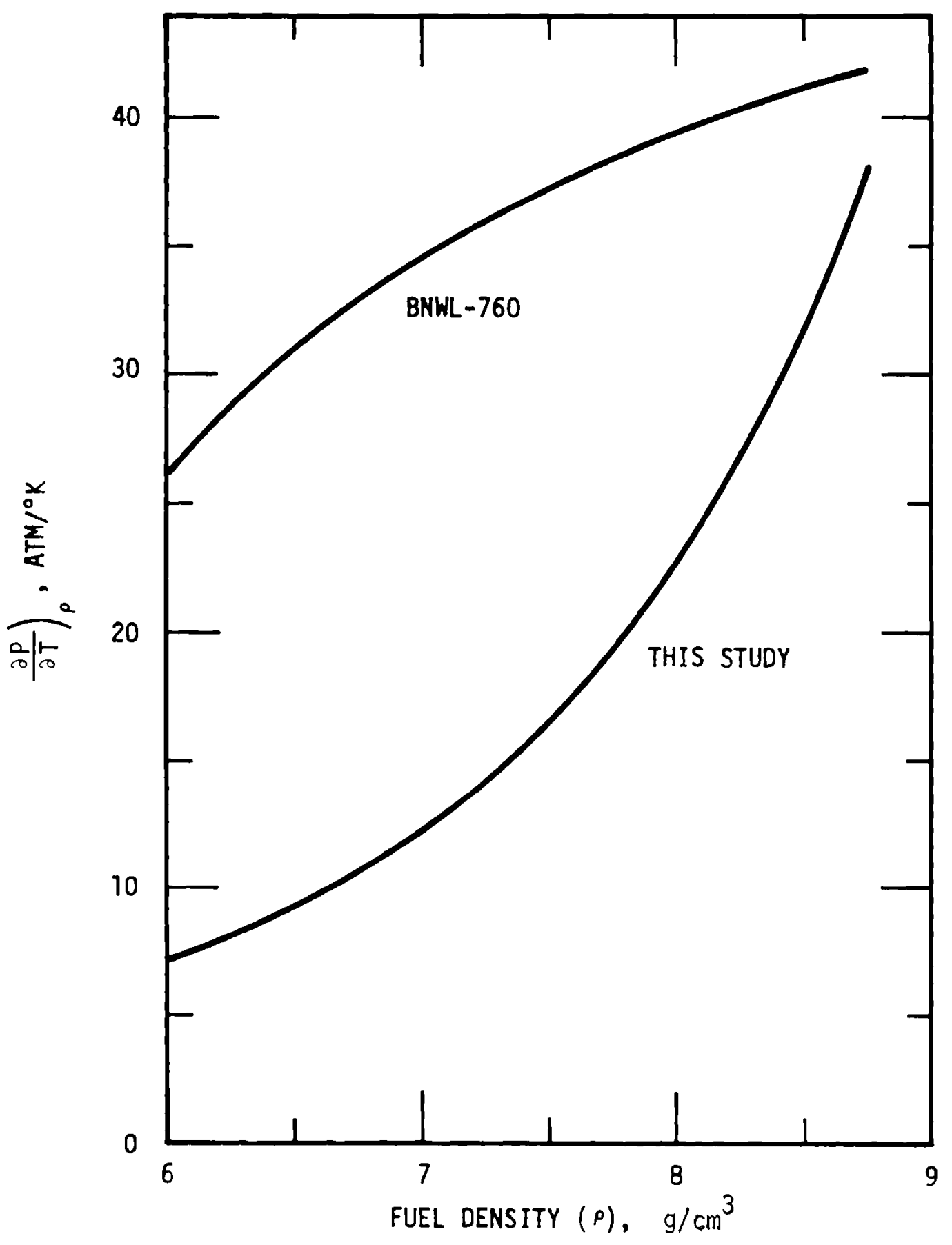

FIGURE 3. Comparison of Pressure-Temperature Slopes in Liquid Fue? 
BNWL - 760

Supplement 1

where

$\left.\frac{\partial \mathrm{P}}{\partial \mathrm{T}}\right)_{\rho}$ is given by Equation (3),

$\mathrm{T}_{\mathrm{d}}$ is given by Equation (2), and

$\mathrm{P}_{\mathrm{d}}$ is the pressure of the fuel vapor at the temperature $\mathrm{T}_{\mathrm{d}}$ (Equation 1).

\section{THE EFFECTS OF SODIUM}

The sodium in the core can appreciably change the course of the accident both before (reactivity effects of voiding), and after (sodium as working fluid in expansion) the disassembly process in addition to the disassembly process per se. These effects have been analyzed in BNWL-760. The only effects of sodium to be considered in this study are those which alter the disassemb1y process itself.

In the previous investigation, (1) it was assumed that sodium did not receive heat energy from the fuel during disassembly. Any heat transfer would either cause the liquid sodium to expand or would create sodium vapor. Both processes would probably tend to increase the pressures in the core. Although the heat transferred to the sodium would decrease the fuel temperatures and thus fuel pressures, these decreases would probably be overshadowed by the increased pressures associated with the sodium vapor and the decreases in volume available to the fuel. This area has not been examined in detail, since ignoring it would probably be conservative.

The remaining sodium effect considered was the volume occupied by the sodium. Small changes in the sodium volume cause similar changes in the volume available to the fuel. From the information in Figure 1 , it is easy to deduce that the temperatures at which large pressures occur are strong functions of the volume available to the fuel. In the previous study, it 
BNWL -760

Supplement 1

was assumed that the volume occupied by the sodium remained unchanged during the disassembly phase. As the pressures in a disruptive nuclear excursion increase, however, the volume occupied by the sodium will decrease (if we assume no heat is transferred from the fuel) since sodium has a finite compressibility. This increases the volume available to the fuel and, thus, reduces the fuel density. The exact correspondence between the sodium and fuel volume changes can only be determined by specifying the composition of the reactor core. To illustrate, consider a small core volume element initially containing $\mathrm{M}$ grams of fuel, $\mathrm{V}_{\mathrm{Na}} \mathrm{cm}^{3}$ of sodium, and $\mathrm{V}_{\mathrm{ss}} \mathrm{cm}^{3}$ of inert material. The inert material (i.e., stainless steel) is assumed to be incompressible for this study. If the initial volume of the element is $\mathrm{V}_{\mathrm{T}_{\mathrm{O}}}$, the initial density of the fuel in its available volume is:

$$
\rho_{0}=\frac{\mathrm{M}}{\mathrm{V}_{\mathrm{T}_{\mathrm{O}}}-\mathrm{V}_{\mathrm{Na}}-\mathrm{V}_{\mathrm{S}} \mathrm{O}_{\mathrm{O}}} \text {. }
$$

As the accident progresses, however, the total volume and the volume occupied by the sodium will change. The fuel density then will be

$$
\rho=\frac{M}{\mathrm{~V}_{\mathrm{T}}-\mathrm{V}_{\mathrm{Na}}-\mathrm{V}_{\mathrm{Ss}_{\mathrm{O}}}} \text {, }
$$

where $V_{T}$ and $V_{N a}$ are time-dependent values. $V_{N a}$ can be determined if the sodium adiabatic compressibility $\left(\beta_{s}\right)$ and the pressure (P) are known:

$$
\mathrm{V}_{\mathrm{Na}}=\mathrm{V}_{\mathrm{Na}} \exp \left[-\beta_{\mathrm{S}}\left(\mathrm{P}-\mathrm{P}_{\mathrm{O}}\right)\right]
$$

The computer code used at this laboratory for design basis accident calculations, MAX, (13) initially divides the core into a specified number of volume elements. During the transient, the mass of material in each element remains constant, and the 
BNWL -760

Supplement 1

current volume occupied by the element and current fuel temperature are monitored. The volume occupied by the sodium is not calculated explicitly and, therefore, must be inherent in the equation of state of the fuel material. Under incompressible sodium conditions, Equation (5) can be solved for the fuel density $\rho$ since the current volume is known and $\mathrm{V}_{\mathrm{Na}}$ (which equals $\mathrm{V}_{\mathrm{Na}}$ ), $\mathrm{M}$, and $\mathrm{V}_{\mathrm{SS}}$ are constants characteristic of the core before disassembly. Equation (4) can then be solved for the pressure as a function of fuel temperature. If the sodium has a finite compressibility, however, Equation (5) becomes a function of pressure and Equation (4) can only be solved for pressure by iteration. In order to avoid iterations in the disassembly code, it would be desirable to have an equation similar to Equation (4) in which $\left.\frac{\partial P}{\partial T}\right)_{P}$ is replaced by $\left.\frac{\partial P}{\partial T}\right)_{V_{T}}$, and $\left.\frac{\partial \mathrm{P}}{\partial \mathrm{T}}\right)_{\mathrm{V}_{\mathrm{T}}}, \mathrm{T}_{\mathrm{d}}$, and $\mathrm{P}_{\mathrm{d}}$ become functions only of the current volume occupied by the volume element $\left(V_{T}\right)$. The resulting equation would, of course, be a function not only of the fuel properties but also of the reactor composition and adiabatic compressibility of sodium.

Iterative solutions to Equations (4), (5), and (6) have been obtained for an assumed reactor composition to illustrate the effects of sodium compressibility and to show the feasibility of obtaining an equation of state for the reactor as suggested in the preceding paragraph. The compressibility of sodium was taken from the compilation in Reference 14. A graphical display of these results is shown in Figure 4 . For these calculations, it was assumed that $\beta_{\mathrm{s}}$ was $3.5 \times 10^{-5} \mathrm{~atm}^{-1}$ and constant throughout the accident. Values of $\beta_{S}=0$ and $1 \times 10^{-4}$ were also used in the calculation to show the sensitivity of the results to the sodium compressibility assumed. The assumed reactor composition was: 


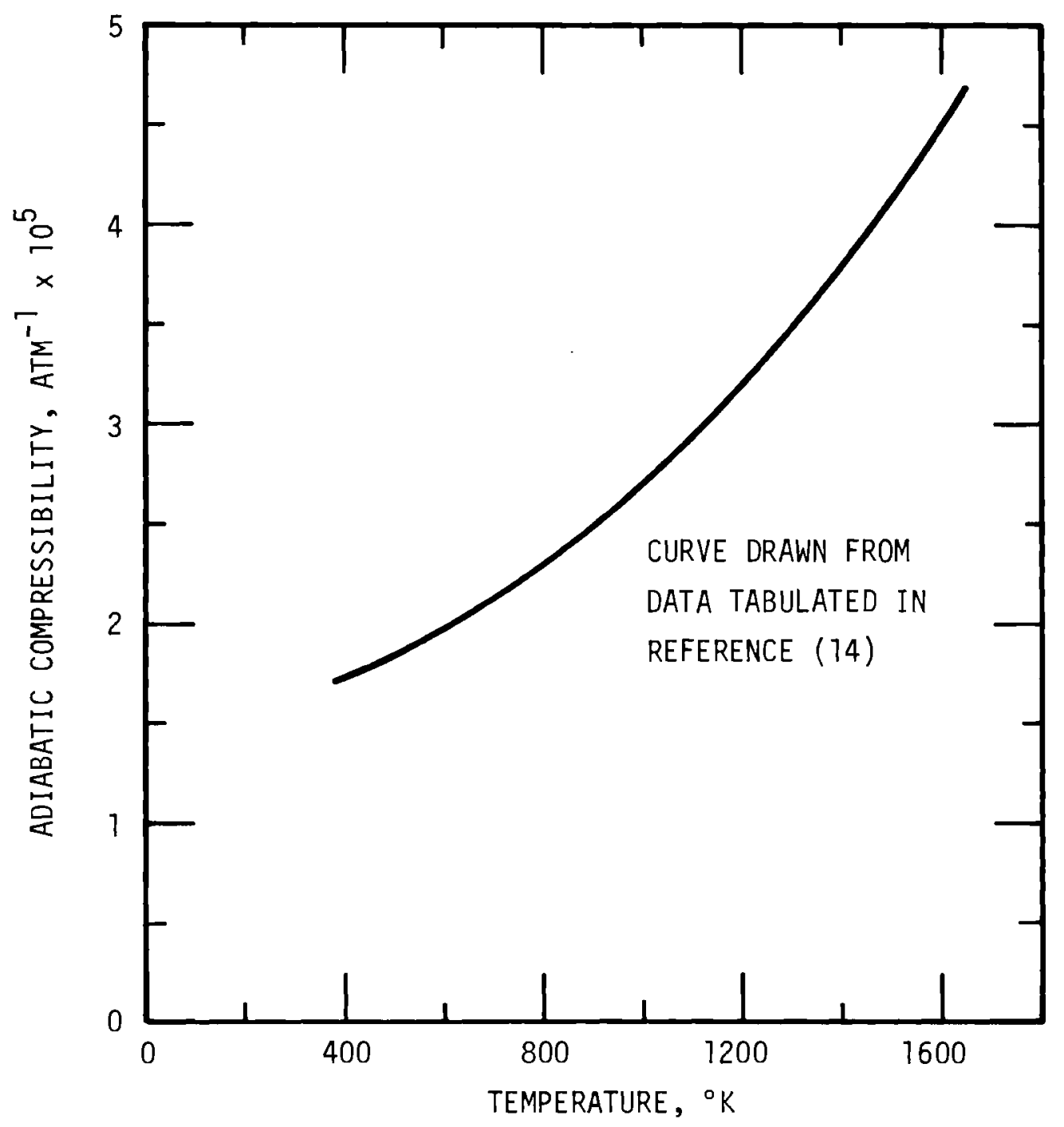

FIGURE 4. Adiabatic Compressibility of Sodium 


$$
\begin{aligned}
& \frac{\mathrm{V}_{\mathrm{Na}}}{\mathrm{V}_{\mathrm{T}_{\mathrm{O}}}}=0.33, \\
& \frac{\mathrm{V}_{\mathrm{S} \mathrm{s}_{\mathrm{O}}}}{\overline{\mathrm{V}_{\mathrm{T}_{\mathrm{O}}}}}=0.29 \quad \text {, and }, \\
& \frac{\mathrm{M}}{\mathrm{V}_{\mathrm{T}_{\mathrm{O}}}}=3.29{\mathrm{~g} / \mathrm{cm}^{3} .}^{3} .
\end{aligned}
$$

The calculated results for several assumed values of $V_{T}$ are shown in Figure 5. The density designations shown on each set of curves are the fuel densities at pressure $=0$, i.e.,

$$
\rho_{0}=\frac{M}{V_{T_{0}}-V_{\mathrm{Na}_{0}}-\bar{V}_{\mathrm{SS}_{\mathrm{O}}}} \text {. }
$$

From the figure, it can be seen that assuming $\left.\frac{\partial P}{\partial T}\right)_{V_{T}}$ is a function only of $V_{T}$ is a good approximation. Thus, if $\left.\frac{\partial P}{\partial T}\right)_{V_{T}}$ and $\mathrm{T}_{\mathrm{d}}$ [and thus $\mathrm{P}_{\mathrm{d}}$ from Equation (1)] are fitted to functions of $\mathrm{V}_{\mathrm{T}}$, an equation of state can be generated which can be used directly in the computer code MAX. (13)

Figure 5 also shows the effects of the compressibility of sodium. Both the shapes of the pressure temperature curves in the liquid fuel region and the temperatures $\left(\mathrm{T}_{d}\right)$ at which these pressures begin are affected. Figures 6 and 7 show these effects in more detail.

The compressibility of sodium was also taken into account in calculating the pressures existing in the cold (solid) fuel regions of the reactor. The pressures exerted by the fuel are assumed to be zero. If the fuel is in the solid phase, however, pressures can arise in such zones if they are compressed by 


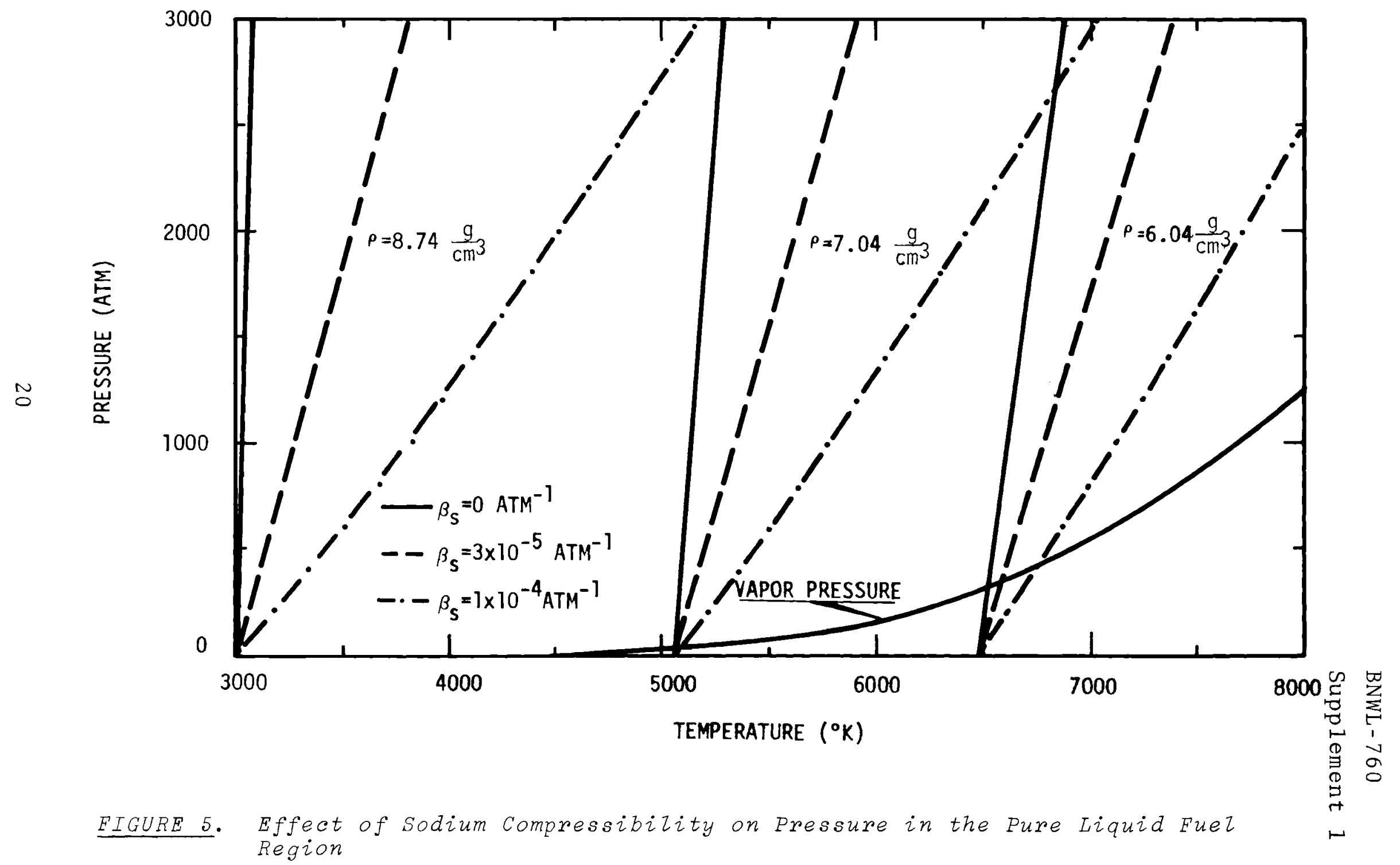




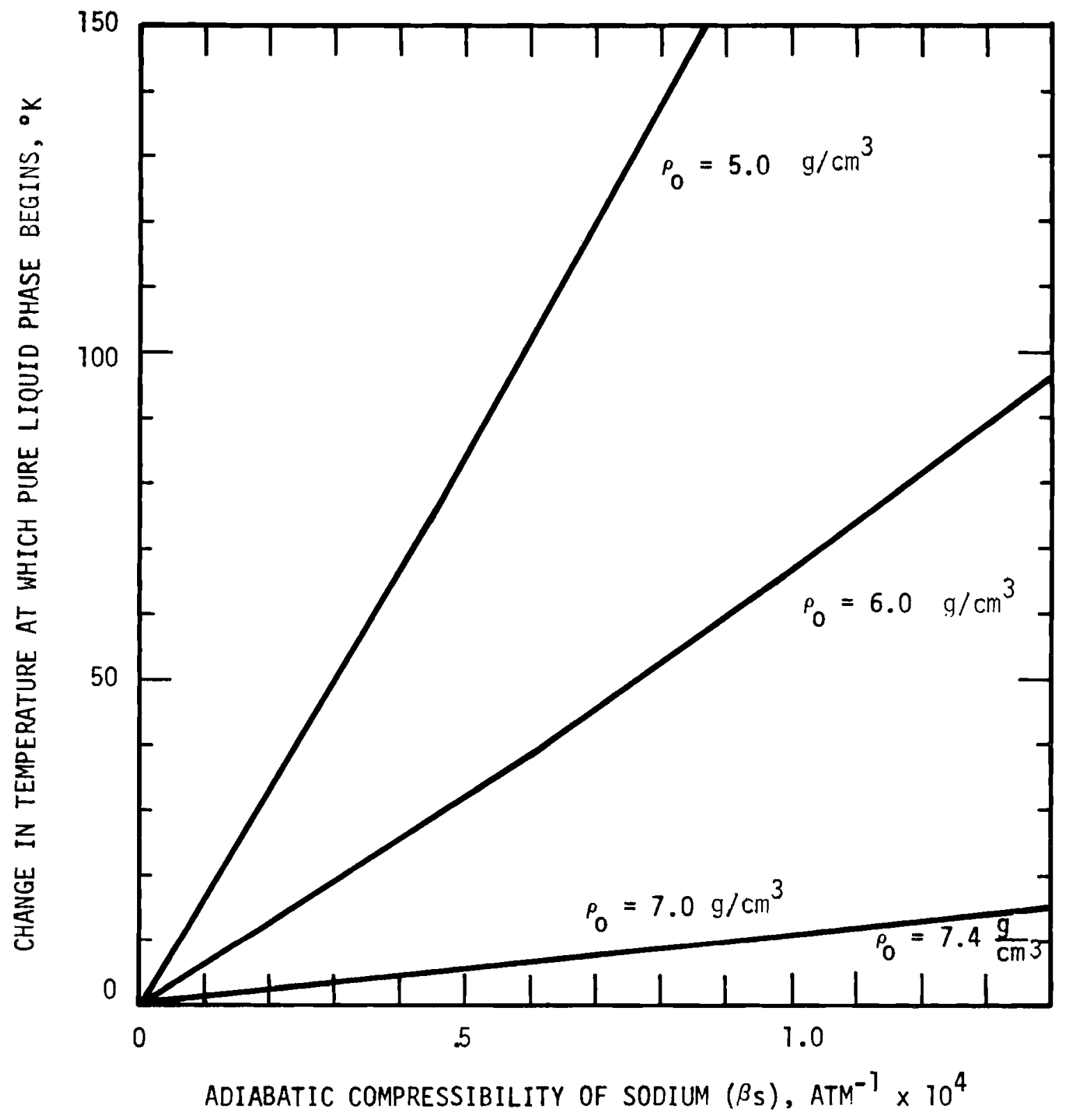

EIGURE 6. Effect of Sodium Compressibility on Temperature at which Pure Liquid Fuel Phase Begins 
BNWL - 760

Supplement 1

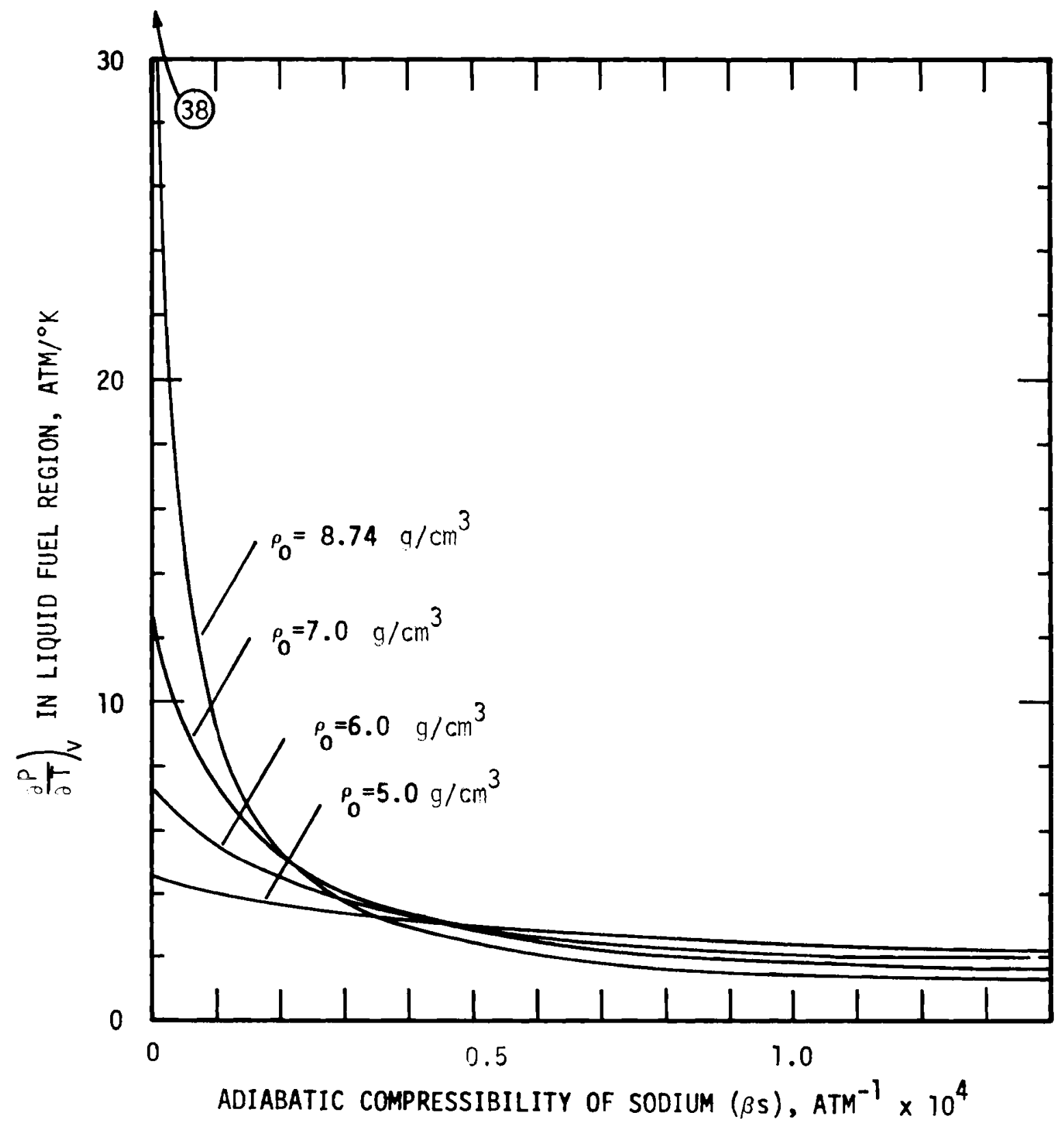

FIGURE 7. Effect of Sodium Compressibility on Pressure Temperature slopes in Pure Liquid Fuel Region 
adjacent hot fuel zones. In these calculations, it is assumed that the solid fuel and inert (stainless steel) materials are incompressible. If the initial void volume $\left(\mathrm{V}_{v_{0}}\right)$ is specified, the pressures existing in solid fuel zones can be calculated from the following equation:

$$
\mathrm{P}=-\ln \left[\frac{\mathrm{V}_{\mathrm{T}}-\mathrm{V}_{\mathrm{T}_{\mathrm{O}}}+\mathrm{V}_{\mathrm{v}_{\mathrm{o}}}}{\mathrm{V}_{\mathrm{Na}}}+1\right] \frac{1}{\beta_{\mathrm{O}}} .
$$

If the resulting pressure is negative, it should be set to zero since this indicates that there is still some void volume in the zone. 
BNWL -760

Supplement 1

\section{SENSITIVITY ANALYSIS OF "SODIUM-IN" CALCULATIONAL METHOD}

The calculational method for "sodium-in" disassembly calculations proposed in the preceding sections requires that values be assigned to certain parameters which may not be known accurately. Furthermore it was stated that the amount of sodium in the core can appreciably affect the calculated energy release. In order to show the effects of the sodium content and to assess the sensitivity to the values assumed for certain parameters, perturbations around a chosen reference sodium-in case were made. This case was identical to that shown in Section 6.2 of BNWL-760, with the exception that the sodium was assumed to be in the core during the disassembly phase. The characteristics of the accident are shown in Figures 8 and 9 , and Tables 2 and 3 . All of the calculations were performed in the MAX ${ }^{(13)}$ computer code. This code calculates the detailed fuel material movement and thus allows a density dependent equation of state.

The measure of the effects of the parameter variations chosen for this investigation was the energy in the molten fuel existing at the end of the nuclear or energy generating phase of the accident. The energy in the molten fuel is defined as that energy above the melting point plus the heat of fusion summed over all of the fuel which is not in the solid state.

The present reference case (using the parameter values shown in Tables 2 and 3 ) resulted in a total energy of $1400 \mathrm{MW}-\mathrm{sec}$ and a peak temperature of $4000^{\circ} \mathrm{K}$. Peak pressures at the end of the transient are not meaningful since the pressures causing disassembly are those characteristics of the liquid fuel phase. These pressures, of course, exist only until small movements take place. Pressures of the order of several thousand atmospheres did, however, exist at times during the transient. Only $81 \%$ of the core was molten at the end of the nuclear portion of the accident. 
BNWL - 760

Supplement 1

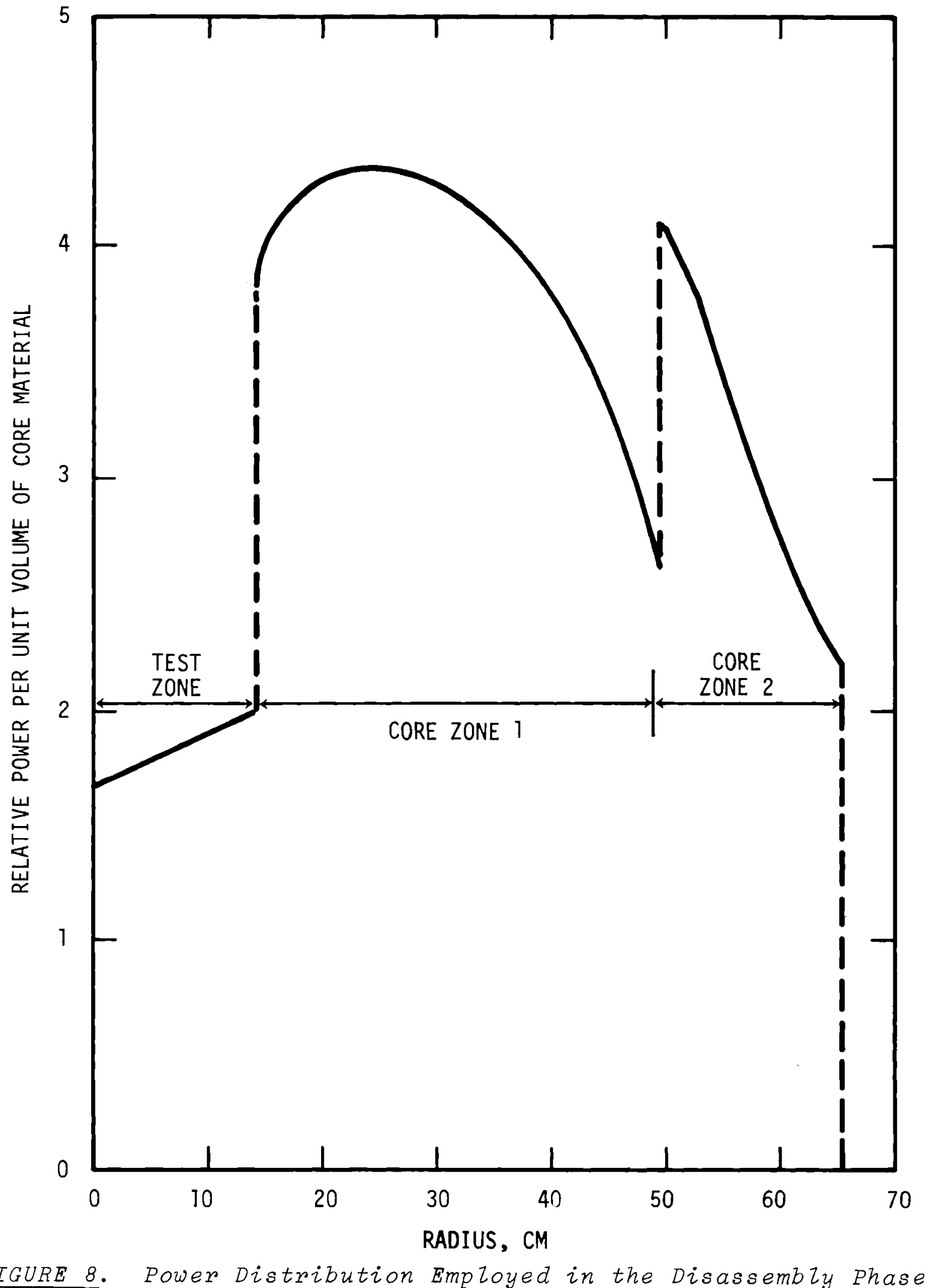


BNWL - 760

Supplement 1

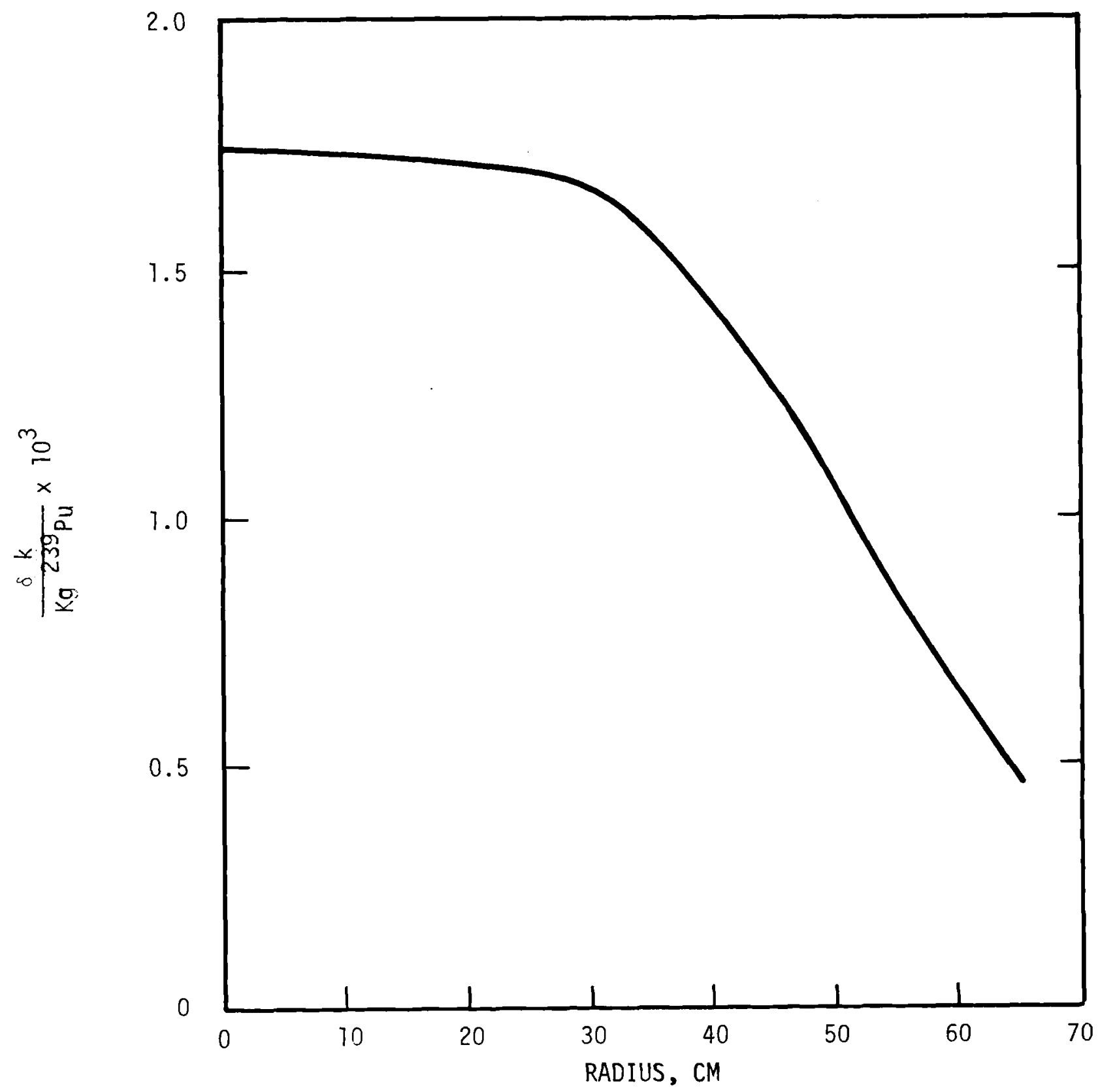

EIGURE 9. Fuel Worth Distribution Employed in the Disassembly Phase 
TABLE 2. Characteristics of the Reference Sodium-In Accident*

Core Volume

Initial Power Level

Initial Temperature

Reactivity Ramp

Doppler Coefficient ( $\mathrm{T} \frac{\mathrm{dk}}{\mathrm{dT}}$ )

Neutron Lifetime

Heat of Fusion

Specific Heat at Constant Volume

Volumetric Coefficient of Expansion of Liquid $\mathrm{UO}_{2}$

Adiabatic Compressibility of Sodium
1163 1iters

$400 \mathrm{MW}$

$1300^{\circ} \mathrm{K}$ (flat)

$100 \$ / \mathrm{sec}$

$-0.0035$

$3.5 \times 10^{-7} \mathrm{sec}$

$280 \mathrm{~J} / \mathrm{g}$

$0.42 \mathrm{~J} / \mathrm{g}-{ }^{\circ} \mathrm{K}$

$1.05 \times 10^{-4}{ }^{\circ} \mathrm{K}^{-1}$

$3.0 \times 10^{-5} \mathrm{~atm}^{-1}$

TABLE 3. Zone Descriptions of Reference Sodium-In Accident*

Zone I Zone II Zone III

(Test) (Inner Driver Fue1) (Outer Driver Fue1)

Zone Thickness, $\mathrm{cm}$
35

3.29

0.29

0.38

0.38

* Same as the reference accident in BNWL-760(1) except that sodium is presently included in the core.

** The initial sodium volume fractions in the driver fuel and test zones were reduced to values of 0.33 and 0.435 respectively for the reference case to approximately account for fuel sintering (see discussion of sensitivity of sodium content). 
BNWL -760

Supplement 1

The density of the liquid fuel (and thus, the temperature at which the fuel vapor phase disappears) is a function of both the assumed fuel density at the melting point in the liquid phase and the volumetric coefficient of expansion $(\alpha)$. The range of a values investigated was quite large ( $\sim 50 \%)$ since no experimental error was quoted for the measurements from which the reference value was derived. As shown in Figure 10, this range yields significant changes in the energy generated in the reference accident. Near the assumed value of $1.05 \times 10^{-4}{ }^{\circ} \mathrm{K}^{-1}$, a $10 \%$ change in a results in an energy change of about $3 \%$. The changes in the energy generated that accompany changes in the assumed density of the liquid fuel at the melting point are shown in Figure 11. The limits of the experimental error for this parameter yield energy changes of about $\pm 14 \%$. Calculations for densities below $8.65 \mathrm{~g} / \mathrm{cm}^{3}$ were not made since in these instances, pressures would have been generated in the fuel before the melting process had been completed. This pressure mechanism is not considered by the MAX code. The lower density limit $\left(8.65 \mathrm{~g} / \mathrm{cm}^{3}\right)$ reflects the fact that the fuel may have a volume exterior to the pellet into which it can expand. (See discussion of sensitivity of sodium content.)

Both of the above parameters were based on measurements of $\mathrm{UO}_{2}$ samples. The FTR fuel should exhibit similar properties since it contains a relatively small amount of $\mathrm{PuO}_{2}(\sim 20 \%)$ and the two oxides should behave similarly. No changes in the reference values shown are anticipated unless more refined $\mathrm{UO}_{2}$ measurements or mixed oxide measurements become available.

The most questionable fuel properties assumed for this study are the pressure-temperature slopes in the liquid fue 1 phase. Reducing these by an arbitrary factor of 5 , however, results in an energy increase of on 1 y $4.6 \%$. 
BNWL- 760

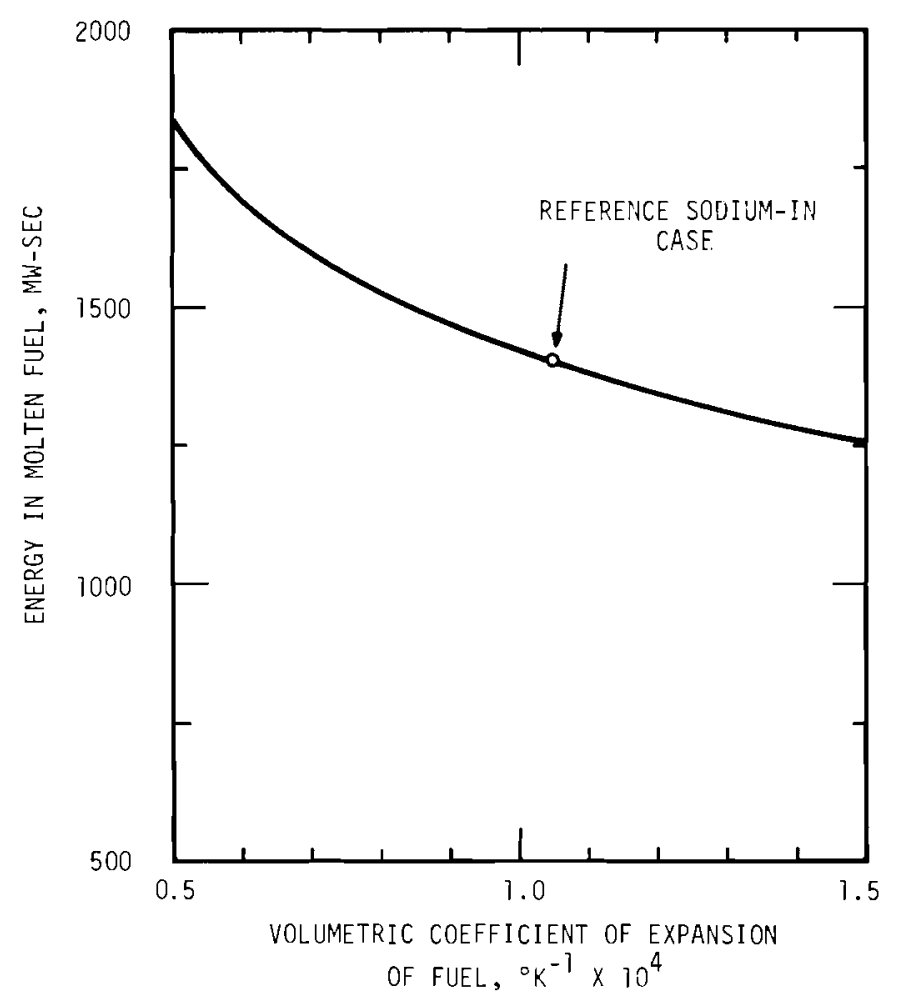

Supplement 1

FIGURE 10. Sensitivity of Volumetric Coefficient of Expansion of Liquid Euel

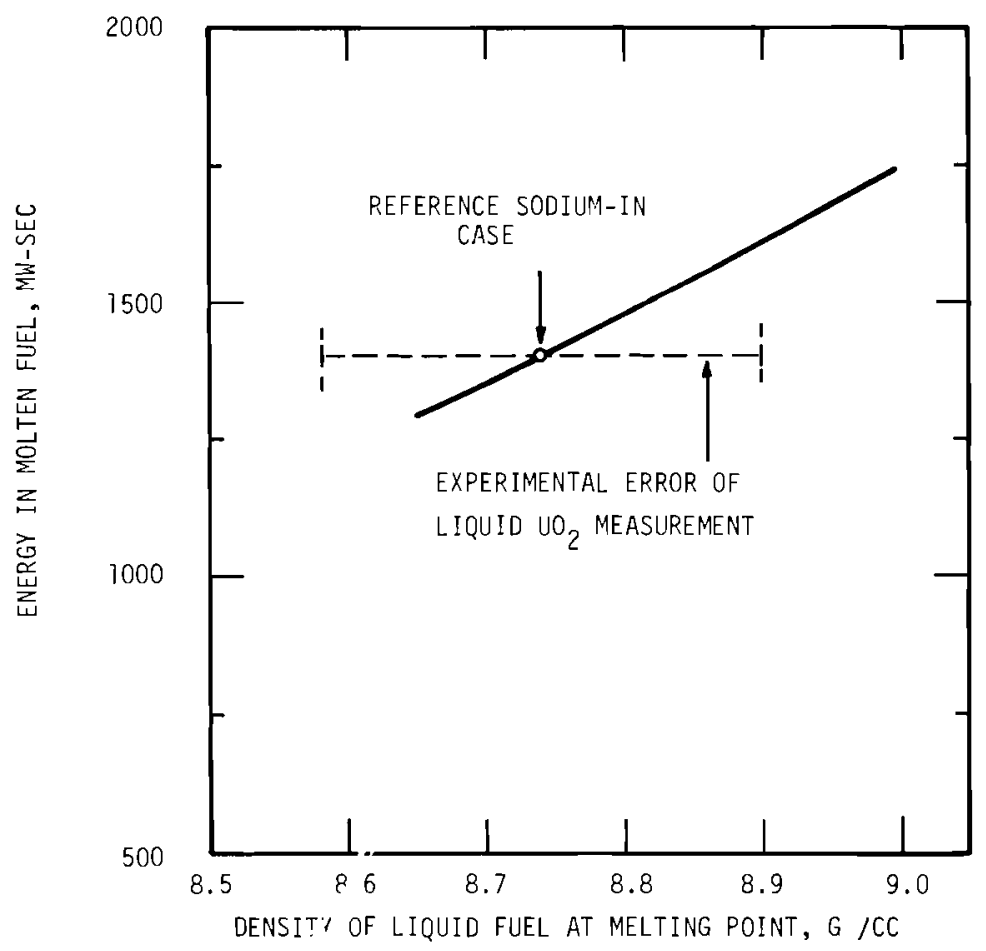

FIGURE 11. Sensitivity of Fuel Density at Melting Point 
BNWL - 760

Supplement 1

The vapor-pressure relationship has little effect on the calculations, since an arbitrary setting at zero caused no change in the calculated energy. This is because the pressures causing disassembly are those of the confined liquid. (At the final peak fuel temperature of $4000^{\circ} \mathrm{K}$, the vapor pressure would be only $1.3 \mathrm{~atm}$ ).

The adiabatic compressibility of sodium has a large effect on the slopes of the pressure-temperature curves in the liquid phase region (Figures 5 and 7 ), and to some extent, affects the temperatures where departure into the liquid phase begins. In Figure 12, the results for large variations in $\beta_{s}$ are shown. Assuming incompressible sodium $\left(\beta_{S}=0.0\right)$ would have resulted in a substantial underestimate of the energy release. Values of $\beta_{S}$ larger than the reference value assumed $\left(3.0 \times 10^{-5} \mathrm{~atm}^{-1}\right)$ would result in small increases in the final energy. However, it is indicated that the reference value is conservative since it is characteristic of a sodium temperature of $1600^{\circ} \mathrm{F}$. This temperature is significantly higher than would occur in the reactor under the adiabatic assumptions made.

As the value of $\beta_{\mathrm{s}}$ increased from 0 to $3 \times 10^{-5} \mathrm{~atm}^{-1}$ in the reference sodium-in case, the predominant effect of variations in $\beta_{S}$ was the change in the slopes of the pressure-temperature curves. Above $\beta_{S}=3 \times 10^{-5} \mathrm{~atm}^{-1}$, however, the changes in the temperatures at which the pure liquid phase begins were most important. This was expected since, from Figures 6 and 7 , it can be seen that the change in the departure temperatures is approximately linear with $\beta$ while the major slope changes for high fuel densities occur below $\beta=3 \times 10^{-5} \mathrm{~atm}^{-1}$.

A basic premise of "sodium-in" calculations is that the presence of sodium will substantially reduce the energy generated in the accident. To illustrate the magnitude of this effect, the amount of sodium was uniformly varied in the reference case. 
BNWL- 760

Supplement 1

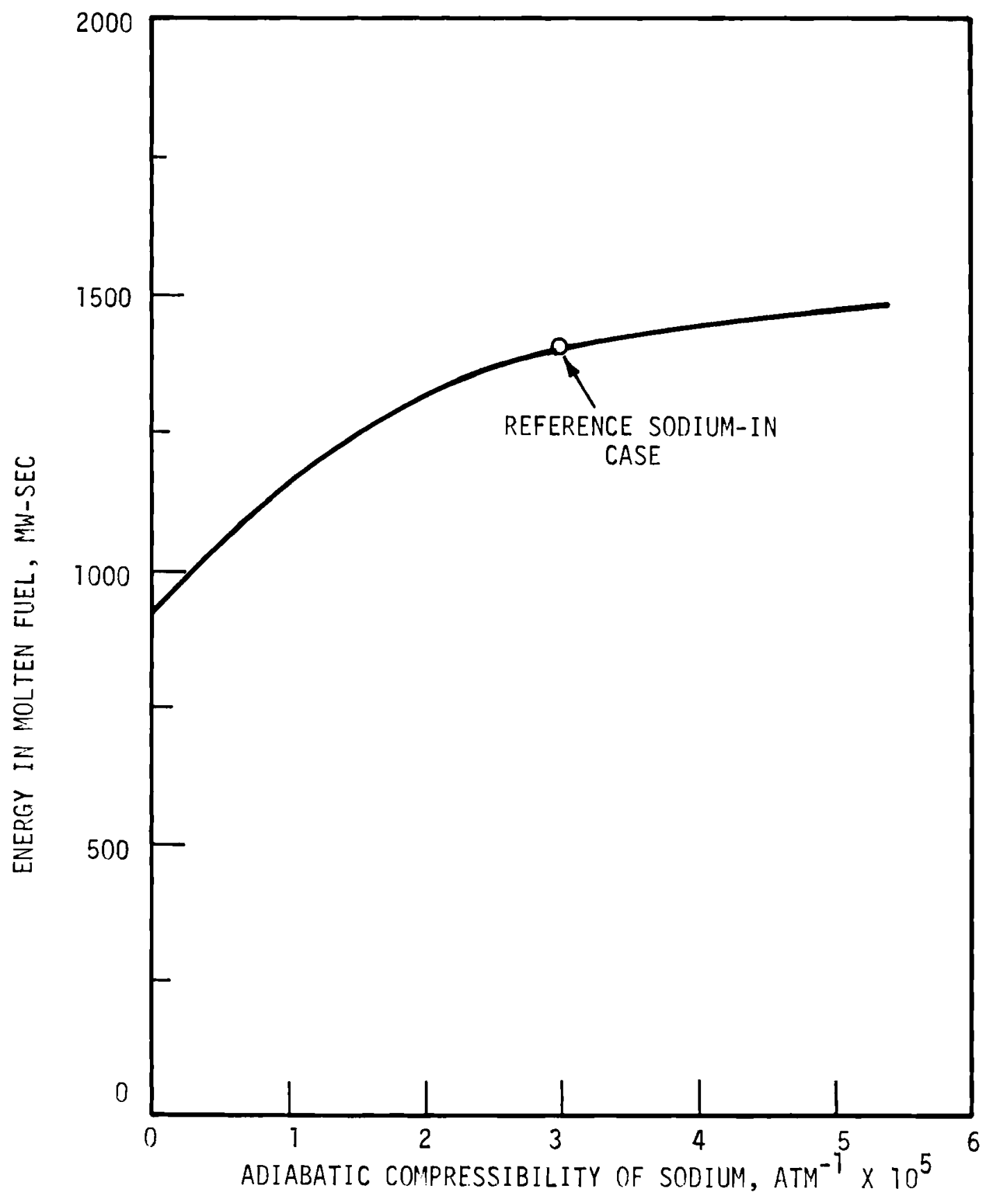

FIGURE 12. Sensitivity of Sodium Compressibizity 
BNWL -760

Supplement 1

The results are shown in Figure 13. It is evident that if more than $70 \%$ of the original sodium inventory is in the core, the final energy decreases rapidly with increases in the sodium content. This variation reflects the changes in the temperatures at which the pure liquid fuel phase begins. It should be noted that calculations were not made above $87 \%$ of original sodium remaining. This is a consequence of the "macroscopic" nature of the calculational method. In MAX, it is assumed that the void within the fuel pin is uniformly distributed over the length and that the voids in one section of the pin are not available to the fuel in an adjacent section. If sintering has occurred in an actual pin, however, a cylin. drical void will appear in the center of the pin. Thus, a molten pellet next to a solid one will be exposed to not only its own void, but the cylindrical void through all of the adjacent unmolten pellets. In an actual disruptive accident, however, the molten fuel cannot occupy all of the available void volume, since melting will propagate rapidly down the pin and the inertia of the molten fuel will inhibit its movement. To approximately account for this effect, the volume associated with each fuel segment was arbitrarily increased by $15 \%$ (by decreasing the associated sodium volume). The $87 \%$ sodium case was taken as the "ful1" sodium case for this study.

The flat and slightly curved portions of Figure 13 are characteristic of the particular reference "sodium-in" accident chosen. Below about $50 \%$ sodium, the accident has terminated before the fuel has expanded to fill the voids. The disassembly pressures are, therefore, those of the fuel vapor. From 50\% to $70 \%$ sodium the importance of the pressures characteristic of the confined liquid fuel increases. A quantitative estimate of the point at which the sodium becomes important can be made from the final peak fuel temperature $\left(5760^{\circ} \mathrm{K}\right)$ in the "sodiumout" case. If it is assumed that no core material movement 
BNWL - 760

Supplement 1

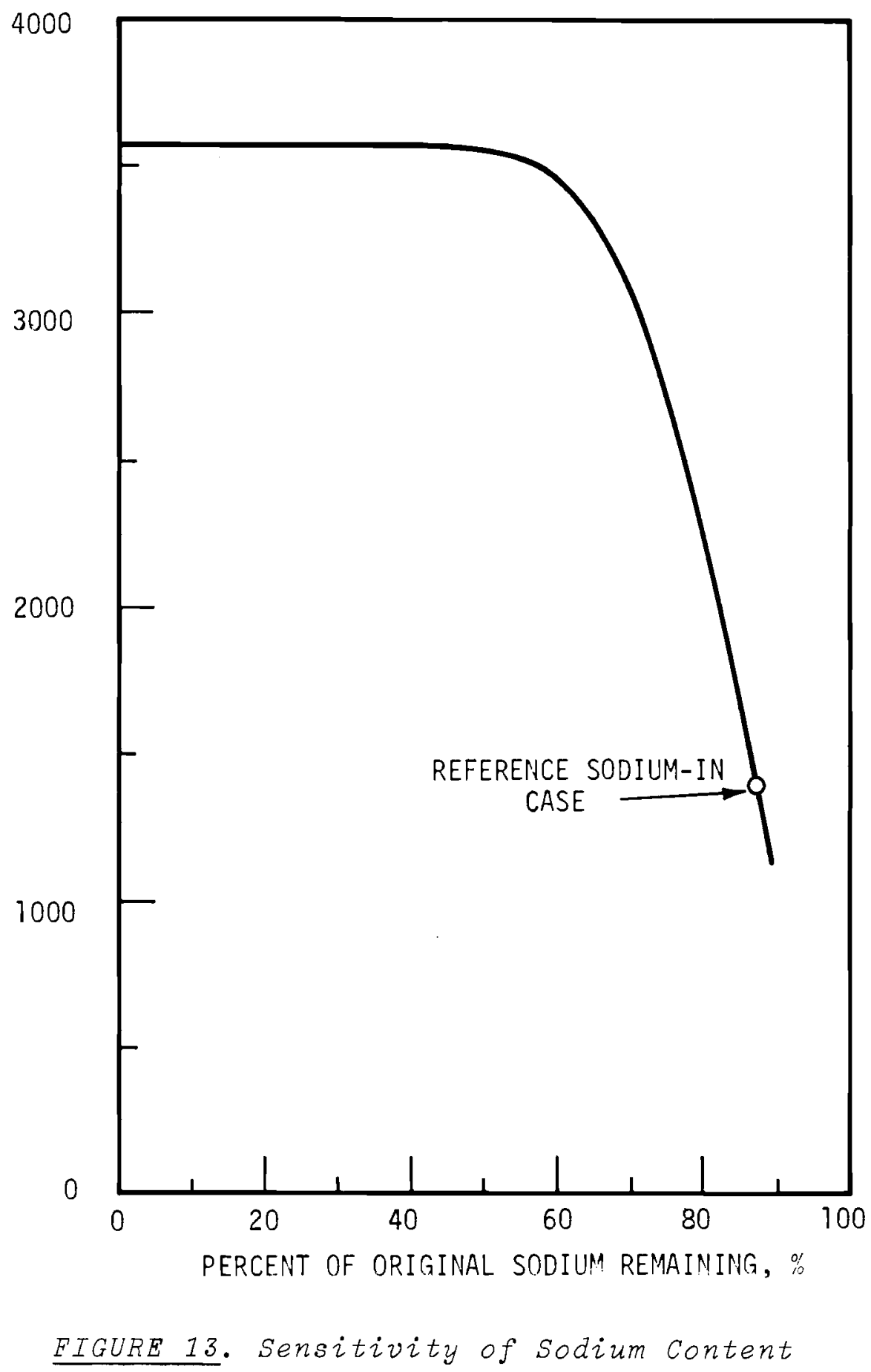


BNWL -760

Supplement 1

takes place, the fuel in the hottest point in the core will fill the available volume at $5760^{\circ} \mathrm{K}$ if $48 \%$ of the sodium is in the core. This value agrees quite well with Figure 13.

Care should be exercised in applying the sodium content sensitivity results to disassembly accident calculations, since the cases shown assumed that the sodium was lost uniformly throughout the core. In an actual accident, the sodium will remain in the core except possibly in small isolated regions. In such instances, the sensitivity to the sodium content would be substantially less than that shown in Figure 13. The sensitivity of the final results to variations in the chosen calculation parameters shown in this section are, of course, applicable only to the reference "sodium-in" case. The results do indicate, however, the order of magnitude of the effects of changes to the fuel and sodium characteristics. 
. 
BNWL -760

Supplement 1

V. APPLICATION TO FTR

The calculational method for "sodium-in" conditions described in the preceding sections of this report is, in some respects, substantially different from that used in analyzing the accidents in the previous issue of BNWL-760. The temperatures at which the large pressures of the confined liquid begin were much higher in the previous analysis. However, the effects of sodium compressibility were ignored. Also, the previous analysis did not allow regions to move unless the contained fuel was molten; the present method permits such movement. The overall consequences of changing the method of calculation are not obvious since the effects of the differences just described on the final energy may cancel each other. A quantitative estimate of the effects of the present method was obtained by recalculating the disassembly phase of a representative case from BNWL-760.

The case chosen for comparison was the shutdown "sodium-in" accident summarized as Case III in Table XII (Page 100) of BNWL760. The reactor parameters are the same as those shown in Figures 8 and 9 , and Tables 2 and 3 with the following exceptions:

$$
\begin{array}{lll}
\text { Initial Power Level } & =2 \mathrm{~kW} \\
\text { Initial Temperature } & =300{ }^{\circ} \mathrm{K} \text { (flat) } \\
\text { Doppler Coefficient (T } \left.\frac{\mathrm{dk}}{\mathrm{dT}}\right) & =-0.003
\end{array}
$$

The accident was followed in the MELT-I(15) code until a significant amount of fuel had melted. The calculation was then transferred to the disassembly code MAX. (13) In the MELT calculation, the reactivity feedbacks resulting from both core collapse and sodium voiding were determined. The feedback induced by collapse was negligible. However, the sodium voiding resulted in an effective reactivity ramp at the time of disassembly of about $250 \$ / \mathrm{sec}$. The other reactor parameters at the time of disassembly (initial conditions for MAX code) were taken from the MELT-I output and were, of course, independent of the disassembly calculational method. 
BNWL -760

Supplement 1

The disassembly calculation in BNWL-760 assumed that all of the sodium had voided in the inner fuel zone. In a small region near the power peak in this zone, it was assumed that there was a residual sodium vapor with a pressure of $100 \mathrm{~atm}$. This pressure was included as a conservative (about 1/5) estimate of the pressures used in calculating the sodium voiding rate for the voiding reactivity. It was assumed to be constant and was added to any fuel pressures calculated during the transient. The resulting final energy in molten fuel was $2000 \mathrm{MW}-\mathrm{sec}$, and the final average temperature of the molten fuel $(3250 \mathrm{~kg})$ was $3800^{\circ} \mathrm{K}$.

A similar calculation was made with the present method assuming that $87 \%$ of the sodium was present in al1 regions of the reactor except those assumed to have voided prior to disassembly. The reduction in the sodium content was made to account approximately for the additional volume available to the molten fuel due to fuel sintering (see section IV). It should be noted that local voiding was assumed instead of entire zone voiding as in the previous calculation. The resulting final energy was quite low (about 120 MW-sec) and was not considered reasonable since the accident was terminated before any fuel nodes in the MAX calculation had completely undergone melting. This occurred because the temperature distribution in the spherical MAX calculation smears out the fine detail of the temperatures calculated in MELT-I. At the time of transfer to the MAX code, MELT-I showed that fue 1 melting (and thus fuel pressures) had occurred at several points in the reactor. These pressures would have inhibited the fuel movement caused by the sodium vapor. The previous calculations in BNWL-760 did not exhibit this phenomenon since material movement was not allowed to take place until local fuel melting occurred. 
BNWL - 760

Supplement 1

A conservative correction to account for the approximate nature of the MAX temperature distribution was made to the calculation. The sodium vapor pressure was set to zero until the hot spot (void of sodium) in the reactor, as simulated in MAX, had reached melting. This resulted in a final energy in molten fuel of $1100 \mathrm{MW}-\mathrm{sec}$ and a final average temperature of the molten fuel $(2500 \mathrm{~kg})$ of $3400^{\circ} \mathrm{K}$. This procedure reduces the importance of the sodium vapor pressure, but it should still have a noticeable effect. A check case identical to the one described above, except that the sodium vapor pressure was ignored, yielded a final energy of 1650 MW-sec: an increase of $50 \%$. Indeed the sodium vapor pressure was found to be even more important than the fuel pressures characteristic of the "sodium-in" situation. A case assuming no voids (and no sodium pressures) resulted in a final energy of $1390 \mathrm{MW}-\mathrm{sec}(+26 \%)$. The relative importance of the constant sodium vapor pressure as compared with the "sodium-in" fuel pressures was further substantiated by additional cases in which voiding and the associated sodium vapor pressure occurred in successively more points in the reactor. The positions and times at which voiding occurred were determined by the beginning of local fuel melting. In all instances, the larger the number of voided regions, the lower the final energy. The pressure induced by the sodium vapor in the voided regions of the core is, thus, quite important to the disassembly process. The assumed value should, if anything, be increased to approximate more closely the pressures used in determining the high sodium voiding ramp rate.

The present calculational method thus results in a significant reduction in the final energy of the molten fue 1 ( $1100 \mathrm{MW}$ sec versus $2000 \mathrm{MW}-\mathrm{sec}$ ) for the "sodium-in" case considered. A similar reduction would thus be anticipated for the at power case shown in Table 6.5 of BNWL-760 as Case $I$ and, thus, the previous calculations (1) were pessimistic. 
BNWL -760

VI. DISCUSSION

The method presented in this report for analyzing the disassembly of a core containing sodium in a violent nuclear excursion is admittedly only an approximation of the phenomenon which might occur in an actual accidert. Several simplifying assumptiors were made to make the calculations tractable. However, in most instances these assumptions were conservative in that the resulting method tenás to underestimate the disassembly forces and thus overestimate the energy generated.

Basic to the method is the equation of state assumed for the fuel material. The derived relationship should describe the fuel adequately at temperatures below about $6000^{\circ} \mathrm{K}$ and at any possible density since it is based, for the most part, on experimental data. The most sensitive parameters are those which describe the liquid fuel density as a function of temperature. Changes to reflect the mixed oxide fuel $\left(\mathrm{PuO}_{2}-\right.$ $\mathrm{UO}_{2}$ ) planned for the FTR should be made as the data from actual measurements of either $\mathrm{PuO}_{2}$ or $\mathrm{PuO}_{2}-\mathrm{UO}_{2}$ become available. However, large variations from the assumed values are not anticipated since the two oxides generally behave similarly. Using the equation of state for fuel temperatures above $6000^{\circ} \mathrm{K}$ is not recommended since the functional relationship used to extrapolate the measured data were derived only for a low temperature fit.

The only effect of the sodium coolant considered in the method is the volume it occupies in the core. As shown in Figure 12, the compressibility of this material nust be included in the calculations in order to avoid underestimating the energy generated in the disassembly phase. The obvious direct result of including the sodium in the disassembly calculation is that it restricts the volume available to the fuel and thus allows the high pressures associated with the confined liquid fuel to exist. As shown in Figure 13, this 
BNWL -760

Supplement 1

results in a major reduction in the energy generated. A further (and still quite important) consequence of the volume occupied by the sodium is that it reduces the voids in the unmolten fue 1 zones. This allows the pressures existing in the hot (molten fue1) zones to be transmitted more easily to the outer edge of the reactor, enhancing disassembly. As illustrated in section $V$, completely voiding the region in the core most important to disassembly (the hottest point in the inner driver zone) and ignoring any residual sodium vapor results in an energy increase of on 1 y about $19 \%$ (1390 $\mathrm{MW}-\mathrm{sec}$ to $1650 \mathrm{MW}-\mathrm{sec})$.

The basic calculational method as presented in Section II was used to analyze one of the "sodium-in" calculations presented in BNWL-760. In this calculation additional conservative corrections were applied to reflect the system being analyzed and to correct approximately for the macroscopic detail of the MAX computer code. These corrections were made to account for:

1) The void which may exist in solid fuel pellets adjacent to molten ones if sintering has occurred,

2) The lack of temperature detail in the reactor as mocked up in MAX, and

3) The sodium vapor pressure assumed in expelling the sodium prior to disassembly.

The resulting calculations clearly revealed the importance of the residual sodium vapor pressure (in the voided regions of the reactor) in contributing to rapid core disassembly. Furthermore, the results indicate that the "sodium-in" energy release calculations in BNWL-760 were probably quite conservative. The latter conclusion is tentative, however, since the present calculations were all done for a particular value of the Doppler coefficient and variations in this parameter are known to have a sizeable effect on energy release. 
BNWL - 760

Supplement 1

Several major areas of uncertainty still remain in "sodium-in" disassembly calculations and should be investigated.

A few of these are enumerated below:

1) In a11 instances the movement of the core was assumed to be inhibited only by its inertial mass. For the cases shown in this report, the forces existing in the core are of the order of several thousand atmospheres and, consequently, the fuel cladding and the subassembly sides should rupture quite easily. If later revisions to other portions of the calculation reduce the magnitudes of the accidents analyzed, the structural effects may become important.

2) The disassembly calculations were carried out in a onedimensional computer code. This has been shown to be adequate for large accidents. However, if a two-dimensional code (allowing for fuel density changes) were available, the approximations necessary to correct for the smeared temperature distribution in the MAX code would not be required.

3) The specific heat of the fuel material was assumed to be constant for both the liquid and solid fuel phases and equal to $0.42 \mathrm{~J} / \mathrm{g}^{\circ}{ }^{\circ} \mathrm{K}$. This should be investigated since the magnitude of the fuel specific heat affects both the Doppler reactivity feedback and the fuel pressures.

4) As shown in Section IV, the pressures exerted by the sodium vapor can appreciably enhance the disassembly process. In the FTR calculations the sodium vapor pressure in the voided regions were reduced in the MAX code to about $1 / 5$ of the magnitudes used in originally expelling the sodium and the disassembly effects of these pressures were ignored until fuel melting had 
BNWL - 760

Supplement 1

occurred in the MAX code. Also, it was assumed that no sodium vapor could be formed after disassembly starts. These conservative approaches were taken because the MAX code at present cannot describe the heat transfer from the fuel to the sodium and has no provisions for adequately monitoring the pressure-temperature-density relationship of non-fuel material. Modification of the MAX code to include such provisions would be quite extensive and are not presently planned. Further investigation of the uncertainties involved, however, may justify a more realistic approach within the framework of the present calculation method.

The analysis herein reported indicates that the disassembly calculations reported in BNWL-760 for "sodium-in" conditions are probably quite pessimistic. However, in lieu of the uncertainties still remaining (as mentioned above), it is presently difficult to quantify the degree of pessimism. Further, a reevaluation of the effects of sodium prior to and following the disassembly phase may be necessary before one can confidently recommend energy release values which are substantially lower than those previously reported. 
BNWL - 760

\section{REFERENCES}

1. D. E. Simpson et al. Preliminary Analysis of Postulated Maximum Accidents for the FFTF, BNWL-760. BattelieNorthwest, Richland, Washington, November 1968.

2. A. E. Waltar and $R$. A. Harris. Preliminary Safety Studies for the Nuclear Proof Test Facility, BNWL-611. BattelleNorthwest, Richland, Washington, November 1967.

3. Enrico Fermi Atomic Power Plant, Technical Information and Hazard Summary Report, NP-10458 (Volume 7), Section 6. Available from Division of Technical Information Extension, springfield, Virginia

4. P. J. Persiani, A. Watanabe, U. Wolff, S. Grifoni, and B. Warman. Some Considerations on the Meltdown Problem for FARET, ANL-6935. Argonne National Laboratory, Argonne, Illinois, september 1964.

5. SEFOR Preliminary Safeguards Summary Report, NP-15077. $\overline{A E C}$ Division of Technical Information Extension, oak Ridge, Tennessee.

6. O. A. Hougen, K. M. Watson, and R. A. Ragatz. Chemical Process Principles, Vol. II, Thermodynamics, John Wiley \& Sons, Inc., 1959. 2nd edition.

7. J.A. Christensen. Thermal Expansion and Change in Volume on Melting for Uranium Dioxide, HW-75148. Available from Clearinghouse for Federal scientific and Technical Information, Springfield, Virginia, october 1962.

8. R. J. Ackermann et al. "High Temperature Thermodynamic Properties of Uranium Dioxide," Chemistry and Physics, vol. 25, no. 6, p. 1089. 1956.

9. D. Milzer. "A Critical Review of the Properties of Materials at the High Temperatures and Pressures Significant for Fast Reactor Safety," Proceedings of the Conference on Safety, Fuels, and Core Design in Large Power Reactors, October 11-14, 1965, ANL-7120, Argonne National Laboratory, Argonne, Illinois.

10. R. A. Meyer et al. Fast Reactor Meltdown Accidents Using Bethe-Tait Analysis, GEAP-4809. General Electric Company, Schenectady, New York, January 1967. 
BNWL -760

\section{Supplement 1}

11. D. C. Menzies. The Equation of State of Uranium Dioxide at High Temperatures and Pressures, TRG-Report-1119(D). United Kingdom Atomic Energy Authority, Harwelz, Berks, England, 1966 .

12. E. J. Robbins. Limits for the Equation of State of Uranium Dioxide, TRG-Report-1344(R). United Kingdom Atomic Energy Authority, Harwell, Berks, England, 1966.

13. W. W. Little, Jr. MAX - A One-Dimensional Maximum Hypothetical Accident Code in Fortran IV, BNWL-612. BattelleNorthwest, Richland, Washington, March 1968.

14. G. H. Golden, J. V. Tokar, and D. Milzer. "Thermophysical Properties of Sodium-Recommended Values," Reactor and Fuel Processing Technology, vol. 11, no. 1, p. 27.1967.

15. A. E. Waltar. MELT-I A Simplified Core Meltdown Code for Fast Reactor Safety Analysis, BNWL-944. Battelle-Northwest, Richland, Washington, December 1968. 
BNWL -760

Supplement 1

\section{DISTRI BUT I ON}

No. of

Copies

OFFSITE

1

33

\section{AEC Chicago Patent Group}

G. H. Lee

AEC Division of Reactor Development and Technology

M. Shaw, Director, RDT

Asst Dir for Nuclear Safety

Analysis \& Evaluation Branch, RDT:NS

T. G. Schleiter

Environmental \& Sanitary Engineering Branch, RDT ; NS

Research \& Development Branch, RDT:NS

Asst Dir for Plant Engineering Branch, RDT

Facilities Branch, RDT:PE

Components Branch, RDT:PE

Instrumentation \& Control Branch, RDT:PE

Liquid Metal Systems Branch, RDT:PE

Asst Dir for Program Analysis, RDT

Asst Dir for Project Management, RDT

Liquid Metals Projects Branch, RDT:PM

FFTF Project Manager, RDT:PM (3)

Asst Dir for Reactor Engineering, RDT

Contro1 Mechanisms Branch, RDT:RE

Core Design Branch, RDT:RE, D. E. Emon

Fue1 Engineering Branch, RDT:RE

Fuel Handling Branch, RDT:RE

Reactor Vessels Branch, RDT:RE

Asst Dir for Reactor Technology, RDT

Coolant Chemistry Branch, RDT:RT

Fuel Recycle Branch, RDT:RT

Fuels \& Materials Branch, RDT:RT

Reactor Physics Brarch, RDT:RT

Special Technology Branch, RDT:RT

Asst Dir for Engrg Standards, RDT

218 AEC Division of Technical Information Extension

1 AEC Idaho Operations office

Nuclear Technology Division

C. W. Bills, Director

Distr -1 
BNWL -760

Supplement 1

No. of

Copies

1

AEC San Francisco Operations Office

Director, Reactor Division

4

AEC Site Representatives

Argonne National Laboratory

Atomics International

Atomic Power Development Associates, Inc.

General Electric

Argonne National Laboratory

L. Baker

C. E. Dickerman

R. Jaross

N. J. Swanson

LMFBR Program office

8

Atomics International

D. J. Cockeram

R. W. Dickinson

Liquid Metal Engrg Center

J. J. Droher (2)

1 Atomic Power Development Associates

Document Librarian

2 Babcock \& Wilcox Co.

Atomic Energy Division

G. B. Garton

S. H. Esleck

$6 \quad$ Bechte1 Corporation

E. Peterson

J. J. Teachnor, Project Administrator, FFTF

Batte1le-Northwest Representative, (Idaho Falls)

N. A. $\operatorname{Hill}$ (ZPR III)

Distr-2 
BNWL - 760

Supplement 1

No. of

Copies

1

Combustion Engineering

1000 MWe Follow-On Study

W. P. Staker, Project Manager

2

Gulf General Atomic Incorporated (AEC)

D. Coburn

6

General Electric Co.

Advanced Products Operation

Kar1 Cohen

Bertram Wolfe

(3)

Nuclear Systems Programs

D. H. Ahmann

1

1

1

W. O. Harms

Stanford University

Nuclear Division

Division of Mechanical Engineering

R. Sher

1

United Nuclear Corporation

Research and Engineering Center

R. F. DeAnge1is

11

Westinghouse Electric Corporation

Atomic Power Division

Advanced Reactor Systems

J. C. R. Kelly

P. Fox 
No. of

Copies

ONSITE-HANFORD

1

$$
4
$$

4

3

1

2

AEC Chicago Patent Group

R. K. Sharp (Richland)

AEC Richland Operations Office

FFTF Program

G. R. Gallagher

J. M. Shivley

AEC Site Representatives - Batte1le-Northwest

P. G. Holsted

Battelle Memorial Institute

Bechte1 Corporation

D. H. Weiss (Rich1and)

Westinghouse Electric Corp.

Advanced Reactor Systems

R. Strzelecki (Richland)

Batte11e-Northwest

S. O. Arneson

E. R. Astley

A. L. Bement

R. A. Bennett

K. L. Berrett

D. C. Boyd

C. L. Brown

W. L. Bunch

S. H. Bush

C. P. Cabe11

J. J. Cadwe 11

C. M. Cantre11

J. R. Carre11

W. E. Cawley

W. L. Chase

T. T. Claudson

J. C. Cochran
P. D. Cohn

D. L. Condotta

R. R. Cone

G. M. Dalen

E. A. Evans

T. W. Evans

C. L. Fies

L. M. Finch

G. L. Fox

E. E. Garrett

S. M. Gill

F. C. Gronemeyer

V. W. Gustafson

J. W. Hagan

J. P. Hale

J. E. Hanson

R. A. Harris 
Battelle-Northwest

H. Harty

R. A. Harvey

R. E. Heineman

R. J. Hennig

P. L. Hofmann

B. M. Johnson

E. M. Johnston

R. L. Junkins

D. D. Lanning

G. A. Last

W. W. Little

C. E. Love

H. G. Johnson

B. Mann

W. B. McDonald

J. S. McMahon

C. A. Munro

C. R. Nash

A. Padilla

M. G. Patrick

R. D. Peak

R. E. Peterson

H. G. Powers

O. W. Priebe

W. D. Richmond

W. E. Roake

A. R. Schade

L. C. Schwendiman

F. H. Shade 1

D. E. Simpson

R. J. Squires

C. C. Steele

D. D. Stepnewski

D. H. Stewart

G. H. Strong

C. D. Swanson

J. C. Tobin

K. G. Toyoda

R. C. Walker

A. E. Waltar

J. H. Westsik

J. F. Wett

T. W. Withers

N. G. Wittenbrock

M. R. Wood

FFTF Files (20)

Technical Publications

Technical Information

Lega 1

(2) 
